\title{
Monetary Policy, Inflation and the Level of Economic Activity in Brazil After the Real Plan: Stylized Facts from SVAR Models*
}

\author{
Brisne Céspedes ${ }^{\dagger}$, Elcyon Lima ${ }^{\ddagger}$, Alexis Maka ${ }^{\S}$
}

Contents: 1. Introduction; 2. Brazilian Stylized Facts and VARs: A Brief Review of the Literature; 3. Data and Estimation Procedures; 4. "Contemporaneous Causation" and the Identification of Structural VARs; 5. Causal Inference and the Identification of Structural VARs; 6. Monetary Policy Developments since the Real Plan; 7. Basic Model and Results for the First Subsample (1996:07-1998:08); 8. Basic Model and Results for the Second Subsample (1999:03-2004:12); 9. Concluding Remarks.

Keywords: Structural VAR; Monetary Policy; Directed Acyclic Graphs.

JEL Code: E31; C32.

Este artigo obtém alguns fatos estilizados sobre as flutuações de curto prazo da economia brasileira após o Plano Real, dando atenção especial à identificação dos efeitos dos choques da política monetária. Dadas as alterações na política monetária, ocorridos após o Plano Real, optamos por dividir a nossa análise em dois subperíodos (1996:07-1998:08 e 1999:032004:12). Os modelos de Auto-Regressão Vetorial Estrutural (SVAR) foram identificados através do uso de grafos acíclicos direcionados. Em contraste com a maioria das análises feitas para o Brasil, que adotam modelos SVAR, encontramos evidências de que uma política monetária contracionista reduz o nível geral de preços.

This article uncovers some stylized facts about the short run fluctuations of the Brazilian economy after the Real Plan, giving special attention to the identification of the effects of monetary policy shocks. A distinctive feature of this article is the careful attention paid to monetary policy developments after the Real Plan when dividing our sample into two subsamples (1996:07-1998:08 and

\footnotetext{
*Financial support from REDE-IPEA is gratefully acknowledged. The views expressed in this paper are those of the authors and do not necessarily represent those of the IPEA or the Brazilian Ministry of Strategic Affairs.

${ }^{\dagger}$ Instituto de Pesquisa Econômica Aplicada (IPEA), Av. Presidente Antônio Carlos, 51 / 15º andar, Rio de Janeiro, RJ, Brazil. E-mail: brisne.cespedes@ipea.gov.br

${ }^{\ddagger}$ Instituto de Pesquisa Econômica Aplicada (IPEA) and Universidade Estadual do Rio de Janeiro (UERJ). E-mail: elcyon. rocha-lima@ipea.gov.br

$\S$ Instituto de Pesquisa Econômica Aplicada (IPEA), Av. Presidente Antônio Carlos, 51 / 15º andar, Rio de Janeiro, RJ, Brazil. E-mail: alexis.maka@ipea.gov.br
} 
1999:03-2004:12). We use directed acyclic graphs to identify the Structural Vector Autoregression (SVAR) models. In contrast with most SVAR analysis for Brazil, we found empirical evidence that supports the view that a contractionary monetary policy indeed reduces the price level.

\section{INTRODUCTION}

This article investigates the stochastic and dynamic relationship of a group of Brazilian macroeconomic variables (price and industrial production indexes, nominal exchange rate, short and mediumrun nominal interest rates, money, and international reserves) for the period after the Real Plan (1996 - 2004). We adopt, as has become usual in the literature, several SVARs (Structural VARs) models to uncover stylized facts about the short-run impacts of the identified exogenous sources of fluctuations of this selected group of variables, with emphasis on the identification of the effects of monetary policy shocks. Structural inference and policy analysis employing VARs require differentiating between correlation and causation, an issue known as "the identification problem". The practice in the literature has been to use identifying assumptions based on "economic theory" or institutional knowledge to sort out the contemporaneous links among the variables in order to allow correlations to be interpreted causally. Unfortunately, the literature has not yet agreed on a particular set of assumptions for identifying the effects of exogenous shocks to monetary policy.

The choice of identification strategy for monetary policy shocks is still an unresolved dispute in macroeconomics.

There are many recent empirical studies about the dynamic relationship of sets of macroeconomic variables in country-regionBrazil employing SVARs as the framework of their analysis (Fiorencio et al. (1998), Rabanal and Schwartz (2001), Arquete and Jayme Jr. (2003), and Minella (2003), among others). With the exception of Fiorencio et al. (1998), all of them use Cholesky decompositions of the covariance of reduced form VAR disturbances to identify the model. What distinguishes our article from the existing Brazilian literature is the adoption of a procedure that, under certain assumptions regarding the underlying data generating process, uses statistical properties of the sample - more specifically, conditional independence relations between the variables - to select over-identifying restrictions to estimate the SVARs. These restrictions follow from directed acyclic graphs (DAGs) estimated by the TETRAD software developed by Spirtes et al. $(1993,2000)$ using as input the covariance of reduced form VAR disturbances. Another distinguishing characteristic of our article is the careful attention paid to monetary policy developments after the Real Plan in the selection of appropriate subsamples. The first subsample goes from 1996:07 to 1998:08, the period with exchange rate "mini-bands" combined with the adoption of the TBC rate as an informal target for the SELIC rate. The second subsample goes from 1999:03 to 2004:12, the period with free-floating exchange rate and explicit SELIC targeting.

Over the last years there has been a growing interest on graphical models and in particular on those based on DAGs as a general framework to describe and infer causal relations, exploring the connection between causal structure and probability distributions. ${ }^{1}$ These methods have been used in a variety of fields but are unfamiliar to most economists. Swanson and Granger (1997) were the first to apply graphical models to identify contemporaneous causal order of a SVAR, although they restrict the admissible structures to causal chains. Bessler and Lee (2002) use error correction and DAGs to study both lagged and contemporaneous relations in late $19^{\text {th }}$ and early $20^{\text {th }}$ century U.S. data. Demiralp and Hoover (2003) evaluate the PC algorithm employed by TETRAD in a Monte Carlo study and conclude that it is an effective tool of selecting the contemporaneous causal order of SVARs. Awokuse and Bessler (2003) use DAGs to provide over-identifying restrictions on the innovations from a VAR and compare their results

\footnotetext{
${ }^{1}$ See for example, Spirtes et al. (1993, 2000), Pearl (2000), and Lauritzen (2001). For a critical evaluation of the use of graphs for inferring causality see Humphreys and Freedman $(1996,1999)$.
} 
with the ones of Sims (1986). Moneta (2004) use DAGs and the data set of Bernanke and Mihov (1998) to identify the monetary policy shocks and their macroeconomic effects in the U.S.. However, as we discuss later on section 5, the use of DAGs for making causal inferences is subject to an important caveat: as Robins et al. (2003) have shown, causal procedures based on associations of non-experimental data under weak conditions ${ }^{2}$, are not uniformly consistent. That means that for any finite sample, there are no guarantees that the results of the causality tests will converge to the asymptotic (correct) results. ${ }^{3}$

In contrast with most of the VAR analysis of monetary policy shocks for Brazil, we found empirical evidence that supports the view that contractionary monetary policy shocks indeed reduce the price level. ${ }^{4}$ The main results of our basic model are: i) In response to a contractionary short run interest rate innovation, during the 1999-2004 subperiod, the exchange rate appreciates, the output and the price level decrease. However, the output response is faster and the price level responds with a lag of near six months in the basic model; ii) For the 1996-1998 subperiod, the most likely effect of a contractionary short run interest rate innovation is the reduction of the price level, even though there is a large uncertainty in this response, and the reduction of output; iii) Exogenous shocks to the exchange rate are, for the 1999-2004 period, the most important source of inflation rate fluctuation.

The article is organized as follows. Section 2 presents a brief review of the Brazilian literature on macro variables and VARs. Section 3 describes the data and the estimation procedures used. Section 4 explains how the identification of contemporaneous causation allows the identification of VARs. Section 5 shows how the Spirtes-Glymour-Scheines Model can be used to identify the SVARs. Section 6 describes monetary policy developments that followed the Real Plan. Sections 7 and 8 present the basic model and results for the first and the second subsamples, respectively, with section 8 discussing the results of an alternative model that includes money. Finally, we offer some concluding remarks on section 9 .

\section{BRAZILIAN STYLIZED FACTS AND VARS: A BRIEF REVIEW OF THE LITERATURE}

In this section we present a brief review of the recent Brazilian literature related to VARs and groups of macroeconomic variables.

Within the classical approach to VARs we have the studies of Rabanal and Schwartz (2001), Arquete and Jayme Jr. (2003), and Minella (2003), while Fiorencio et al. (1998) use a Bayesian VAR (BVAR) in their analysis.

Fiorencio et al. (1998) use BVAR models to analyze the impacts of monetary and exchange rate policies on unemployment and the price level after the Real Plan. The basic model was estimated for the period between January 1991 and May 1997, with and without intervention on July and August 1994, using as variables the price level (IPCA), the unemployment rate, the exchange rate, the interest rate over capital financing ("capital de giro"), and the spread between capital financing and private bonds (CDBs) rates. Employing a non-recursive identification they find that exchange rate shocks have significative impacts over the price level and unemployment, and that monetary policy shocks do reduce the price level and increase unemployment (in the model with intervention). ${ }^{5}$ According to them the results suggest that there has been a change of regime after the Real Plan and that the effects of economic policy shocks in the model are sensitive to the way this change of regime is represented.

Rabanal and Schwartz (2001) use a VAR to analyze the effectiveness of overnight interest rate (SELIC) as a monetary policy instrument in Brazil and its effects on other interest rates, output, and prices

\footnotetext{
${ }^{2}$ These weak conditions are the Markov and faithfulness assumptions, which are defined on section 5 .

${ }^{3}$ However, it has been shown that under stronger assumptions the procedures for inferring causality based on DAGs are uniformly consistent. See Zhang (2002), Zhang and Spirtes (2003).

${ }^{4}$ None of our results hinge on the use of DAGs or Tetrad to identify the VARs. They may be reproduced by ordinary identification schemes, like the Cholesky decomposition of the covariance matrix.

${ }^{5}$ The impacts of monetary policy shocks over the price level and unemployment are reversed in the model without intervention.
} 
for the period between January 1995 and August 2000. The variables included in the VAR are real output, inflation (IPCA), SELIC rate, lending spreads, and money (M1), used in this order in the recursive (Cholesky) decomposition of the variance-covariance matrix of errors. ${ }^{6}$ They conclude that the SELIC rate has a significant and persistent effect on output and lending spreads but interest rate shocks seemed to increase inflation ("price puzzle").

Arquete and Jayme Jr. (2003) evaluate the impact of monetary policy on inflation and output, covering the period between July 1994 and December 2002. As variables of the model they used inflation (IPCA), SELIC rate, and output gap, employed in this order in the recursive decomposition of errors. ${ }^{7}$ In some of their analysis they also included a fifth variable (alternatively the nominal exchange rate, the real exchange rate, and the international reserves at the Central Bank) intended to capture external constraints in Brazil. According to them monetary policy have real effects, external restrictions and exchange rate volatility are important to the Central Bank reaction function but interest rate shocks increase inflation.

Minella (2003) investigates the macroeconomic relationships involving output, inflation, interest rate, and money, comparing three different periods: January 1975 - July 1985, August 1985 - June 1994, September 1994-December 2000. His basic model includes output, inflation (IGP-DI), nominal interest rate (SELIC rate), and money (M1), used in this order in the Cholesky decomposition. His main results are that monetary policy shocks have significant effects on output but are not able to induce a reduction of inflation, with evidence suggesting the price puzzle in the second sub-period. For the Real Plan period, the results about the effects of monetary policy shocks over inflation are not conclusive.

More recently we have the contributions of Sales and Tannuri-Pianto (2005) and Fernandes and Toro (2005). Sales and Tannuri-Pianto (2005) apply for Brazil the Bernanke and Mihov (1998) methodology that imposes contemporaneous identification restrictions on a set of variables relevant to the market for commercial bank reserves in order to identify monetary policy shocks. Despite the uncertainty associated with their results, all their models displayed an inflation rate puzzle where the rate of change of the price level decreased temporarily in response to an expansionary monetary policy shock, although its effect over the price level is permanent. Fernandes and Toro (2005) estimate the monetary transmission mechanism for Brazil after the Real Plan using a cointegrated VAR model, identifying the cointegrated vectors as equilibrium relationships. They analyze the period from November 1994 to February 2001 as a whole, despite the change in the exchange rate regime that occurred on January 1999, treating changes in international reserves and exchange rate as exogenous variables. According to their results, positive monetary policy shocks, identified as SELIC innovations, have a temporary, short-lived negative effect over the inflation rate, which disappears after six months, implying a permanent effect of monetary policy over the price level.

\section{DATA AND ESTIMATION PROCEDURES}

The models were estimated using monthly data divided into two subsamples: the first goes from 1996:07 to 1998:08 and second from 1999:03 to 2004:12. ${ }^{8}$ The following variables were used: the SELIC interest rate (adjusted average rate of daily financing guaranteed by federal government securities, calculated in the Special Settlement and Custody System (SELIC) and published by the Central Bank of Brazil, annualized rate); the nominal exchange rate (end of period buying rate - source: $B C B$ ); the IPCA (official price index used for targeting inflation - source: IBGE); the 180 days Swap rate (PRE $\mathrm{x}$ CDI - annualized rate considering 252 working days - the original source is the Brazilian Mercantile \&

\footnotetext{
${ }^{6}$ Another ordering is also analyzed: SELIC rate, lending spreads, output, inflation, and money, but the results do not change much.

${ }^{7}$ An alternative order analyzed was: output gap, inflation, SELIC rate.

${ }^{8}$ The reasons for splitting the sample into two subsamples and the particular choice of dates are based on monetary policy developments after the Real Plan and are discussed on section 6.
} 
Futures Exchange but the information that we used was collected from http://www.risktech.com.br/); the Industrial Production index, used as a proxy for output (source: IBGE); net foreign reserves (liquidity concept, as measured by the $\mathrm{BCB}$ ); and a monetary aggregate (M1, working days average).

The VAR reduced forms were estimated equation by equation using ordinary least squares (OLS). Following the results of Sims and Uhlig (1991) and Sims et al. (1990), we do not performed unit root tests or cointegration analysis. ${ }^{9}$

\section{4. “CONTEMPORANEOUS CAUSATION” AND THE IDENTIFICATION OF STRUCTURAL VARS}

\subsection{The Reduced Form VAR Model}

Let $x_{t}$ be the data vector - there are 5 variables in the model, therefore $x_{t}$ has dimension $5 \times 1-$ for each period $\mathrm{t}: x_{t}=\left[r_{t} e_{t} p_{t} r s_{t} Y_{t}\right]^{\prime}$, where: $r_{t}=$ Selic rate; $e_{t}=$ exchange rate $; p_{t}=$ IPCA index; $r s_{t}=$ swap rate (180 days); $Y_{t}=$ industrial production index.

The reduced form VAR model is given by the following set of equations:

$$
\begin{gathered}
B(L) x_{t}=\mu+\phi Z_{t}+\nu_{t} \\
\nu_{t} \sim N(0, \Sigma) \text { and } E\left(\nu_{t} \nu_{s}^{\prime}\right)=0, \forall t \neq s
\end{gathered}
$$

where:

$B(L)=I-\sum_{i=1}^{p} B_{i} L^{i}$ and $L$ is the lag operator;

$Z_{t}=$ seasonal dummies vector;

$\nu_{t}=$ reduced form residuals; and $\mu=$ constants' vector.

This representation of the model does not allow for the identification of the effects of exogenous independent shocks to the variables since the VAR reduced form residuals are contemporaneously correlated (the $\Sigma$ matrix is not diagonal). ${ }^{10}$ That is, the reduced form residuals $\left(\nu_{t}\right)$ can be interpreted as the result of linear combinations of exogenous shocks that are not contemporaneously (in the same instant of time) correlated. It is not possible to distinguish whose exogenous shocks affect the residual of which reduced form equation. The residual can be the result, for example, of an exogenous and independent shock to the exchange rate, an exogenous and independent shock to the interest rate, or a linear combination of both shocks. In evaluations of the model (and of economic policies) it only makes sense to measure exogenous independent shocks. Therefore, it is necessary to present the model in another form where the residuals are not contemporaneously correlated. A VAR where the residuals are not contemporaneously correlated is called a structural VAR and some of its equations have, in general, a behavioral interpretation. The same is not true for reduced form VARs.

\subsection{The Structural Form VAR Model}

The model in structural form is given by:

$$
\begin{gathered}
A(L) x_{t}=\rho+\theta Z_{t}+\epsilon_{t} \\
\epsilon_{t} \sim N(0, D), D \text { (diagonal) e } E\left(\epsilon_{t} \epsilon_{s}^{\prime}\right)=0, \forall t \neq s
\end{gathered}
$$

\footnotetext{
${ }^{9}$ They show that the classical unit roots asymptotics is of little practical value and that the common practice of attempting to transform models into a stationary form by difference or cointegration operators, whenever it appears likely that the data are integrated is in many cases unnecessary.

${ }^{10}$ These shocks are primitive and exogenous forces, with no common causes, that affect the variables of the model.
} 
where $\rho=A_{0} \mu, \theta=A_{0} \phi, A(L)=A_{0} B(L), \epsilon_{t}=A_{0} \nu_{t}, A_{0}$ is a full rank matrix with each element in its main diagonal equal to one.

The relationships between the residuals $\epsilon_{t}$ and $\nu_{t}$, and the covariances $D$ and $\Sigma$, are given by:

$$
\begin{gathered}
\nu_{t}=A(0)^{-1} \epsilon_{t} \text { or alternatively, } \nu_{t}=\left[I-A_{0}\right] \nu_{t}+\epsilon_{t} \\
A_{0} \Sigma A_{0}^{\prime}=D
\end{gathered}
$$

Given an estimate of $A_{0}$ it is possible to estimate structural form parameters from estimates of reduced form parameters. When the reduced form VAR is estimated restricting only the number of lags (chosen as the same in all equations and for all variables), with no further restrictions, the structural VAR estimation proceeds in two steps. ${ }^{11}$ In the first step the reduced form VAR is estimated and this comprise the estimation of the equation's coefficients and of the covariance matrix of the reduced form residuals ( i $\hat{g}$ ma $)$. In the second step the matrices $A_{0}$ and $D$ are estimated using only the information given by the estimate of the covariance matrix of reduced form residuals (estimated in the first step).

There are in general a large number of full rank matrices $A_{0}$ and $D$ ( $D$ diagonal) that allow us to reproduce $\hat{\Sigma}$. That is, there are several conditional dependency and independency contemporaneous relations ("Markov kernels") between the variables - given by different specifications of which parameter in $A_{0}$ is free and which is equal to zero - that allow us to reproduce the partial correlations observed for the reduced form residuals. ${ }^{12}$ In order to estimate the structural model it is necessary to identify a number of conditional independence relations (that is, parameters equal to zero in $A_{0}$ ) to satisfy the order condition for identification. Therefore, identifying $A_{0}$ is equivalent to identifying the conditional distributions ("Markov Kernels") of reduced form residuals from information about their joint distribution. These conditional distributions can be interpreted either distributionally or causally. The causal interpretation requires the knowledge that the conditional distributions would remain invariant under intervention. ${ }^{13}$ For SVARs to be useful, as we will show below, these conditional distributions must have a causal interpretation.

With $A_{0}$ it is also estimated the orthogonal innovations of the structural form and identified the linear combinations between them that generate the reduced form residuals [first version of equation (3)]. Alternatively, the residual of each reduced form equation in period $t$ is modeled as the sum of a single innovation (an exogenous structural shock independent of the other structural shocks) ${ }^{14}$, in period $\mathrm{t}$, plus a linear combination of the remaining reduced form shocks in the same period $t$ (second version of equation (3)). In this step it is thus important to establish a set of contemporaneous causal relations (conditional dependency and independency relations with a causal interpretation) between

\footnotetext{
${ }^{11}$ This two steps procedure can be adopted because the restrictions imposed to estimate the orthogonal residuals do not imply restrictions on the coefficients of the reduced form equations. They imply restrictions only on the variance of $\nu_{t}$.

${ }^{12}$ The matrices $A_{0}$ and $D$ cannot have, together, a number of free parameters bigger than the number of free parameters in the symmetric matrix $\Sigma$. If $n$ is the number of endogenous variables of the model then, to satisfy the order condition for identification of matrices $A_{0}$ and $D$, it is necessary that the number of free parameters to be estimated in $A_{0}$ be no bigger than $n(n-1) / 2$ (matrix $D$ is diagonal with $n$ free parameters to be estimated). When $n$ is smaller than $n(n-1) / 2$ the model is over-identified. There exists no simple general condition for local identification of the parameters of $A_{0}$ and $D$. However, as has been shown by Rothenberg (1971), a necessary and sufficient condition for local identification of any regular point in $R^{n}$ is that the determinant of the information matrix be different from zero. In practice, evaluations of the determinant of the information matrix at some points, randomly chosen in the parameter space, is enough to establish the identification of a certain model.

${ }^{13}$ For an interesting discussion of this topic see Freedman (2004), Hausman and Woodward (1999), and Woodward (1997, 2001).

${ }^{14}$ The exogenous shocks, in each period $t$, are represented by the vector $\epsilon_{t}$. The VAR model is a formalization of the relationship between the vector $\epsilon_{t}$ and the vector of observed data $x_{t}$. Employing the terminology adopted in the Real Business Cycle literature, the $\epsilon_{t}$ are "impulses" (or orthogonal innovations) and the matrices in $\mathrm{A}(\mathrm{L})$ (equation (2)), capture the propagation mechanism of the economy.
} 
the reduced form residuals. That is, we need to determine, for example, whether contemporaneously (within a month, if the model uses monthly data) a shock to the reduced form residual of the exchange rate equation affects the reduced form residual of the interest rate, or the other way around, or whether there is bi-directional causality.

Obtaining stylized facts from VARs requires the identification of the structural form model. The question is: is it possible to obtain the contemporaneous causality relations that may allow the identification the model from the data alone? We describe next how the methodology developed by Spirtes et al. $(1993,2000)$ (hereafter SGS) can help in the identification of the VAR structural form.

\section{CAUSAL INFERENCE AND THE IDENTIFICATION OF STRUCTURAL VARS}

\subsection{Causation and Association in Observational Data}

Common statistical wisdom dictates that causal effects cannot be consistently estimated from observational data (non-experimental data) alone unless one has substantial background knowledge about the data generating mechanism. For this reason the contemporaneous causality restrictions used to identify structural VARs, have been traditionally based on a priori restrictions, some of them arbitrary, others with some help of economic theory. In the mid-1980's, when the mathematical relationships between graphs and probabilistic dependencies came into light, the possibility of inferring causality from data was explored with the development of causal inference techniques based on directed acyclic graphs (DAGs). The subject received a formal treatment and efforts were made toward its computational feasibility. There are two main classes of learning algorithms employed to search the causal structure from data using DAGs: the constraint-based approach and the Bayesian approach. The constraint-based approach uses data to make categorical decisions on whether or not particular conditional independence constraints hold. It tests conditional independence relations among the observed variables, which, under certain assumptions, put some graphical constraints on the possible causal structures. The Bayesian approach applies Bayesian model selection techniques to the search for a causal graph, using data to make probabilistic inferences about conditional independence constraints. For example, rather than accepting that variables $X$ and $Y$ are independent, the Bayesian approach taking into account the uncertainty concerning the presence of independence, infers that $X$ and $Y$ are independent with some probability. In this article we employed the constraint-based methodology developed by SGS in the search of the contemporaneous causal orderings of the variables of the SVARs in order to identify the models. Here we give a brief description of how the SGS procedure is implemented. The details of the SGS model are presented in Appendix I. ${ }^{15}$

SGS developed algorithms for inferring causal relations from data that are embodied in a computer program used in this article, called TETRAD. ${ }^{16}$ We used TETRAD III in this paper.. The program takes as input the covariance matrix of the variables of the model, ${ }^{17}$ converting it into a correlation matrix and performing hypothesis tests in which the null hypothesis is a zero partial correlation. TETRAD begins with a 'saturated' causal graph, where any pair of nodes (variables) is joined by an undirected edge. ${ }^{18}$ If the null hypothesis of zero conditional correlation cannot be rejected - at, say, the $5 \%$ level, using Fisher's $\mathrm{z}$ test - the edge is deleted. After examining all pair of vertices, TETRAD move on to triples, and so forth, orienting the edges left in the graph through the connection between probabilistic

\footnotetext{
${ }^{15}$ For a more detailed description of the Bayesian approach, see Heckerman et al. (1999).

${ }^{16}$ The program is available for download at www.phil.cmu.edu/projects/tetrad/index.html

${ }^{17}$ In our application, the input of TETRAD is the covariance matrix of the reduced form VAR residuals.

${ }^{18} \mathrm{An}$ edge in a graph can be either directed (marked by a single arrowhead on the edge) or undirected (unmarked). Arrows represent causal relationships: if there is an arrow pointing from $X_{i}$ to $X_{j}$ it means that $X_{i}$ has a direct causal effect on $X_{j}$.
} 
independence and graph theory. The final output of TETRAD is a set of observationally equivalent. ${ }^{19}$ DAGs containing the proposed causal structure(s) of the model. Next we show how DAGs can be used to impose restrictions that allow the identification of Structural VARs (SVARs).

\subsection{DAGS and the Identification of Structural VARs}

According to equation (3), the relationship between reduced form and structural form residuals in a VAR is given by:

$$
\nu_{t}=\left[I-A_{0}\right] \nu_{t}+\epsilon_{t}
$$

where:

$\nu_{t}$ - column vector, with dimension $n \times 1$, with reduced form VAR residuals at period $t$;

$\epsilon_{t}$ - column vector, with dimension $n \times 1$, with structural form VAR residual at period $t$; and

$A_{0}$ - full rank matrix with the relationship between the two types of residuals.

Matrix $A_{0}$ gives the causal relations among the contemporaneous variables. A necessary (but not sufficient) condition for identification of the model is that there are at least $n(n-1) / 2$ coefficients equal to zero on $A_{0}$. SGS procedures use DAGs as representation of conditional independence relationships that allow us determine whose coefficients of matrix $A_{0}$ are equal to zero. This is illustrated in the example below, where we assume that the VAR has 3 endogenous variables $(n=3)$.

Suppose that after entering the covariance matrix of the reduced form VAR residuals, TETRAD give us the following DAG as its final output:

Figure 1 - DAG with Explicity Represented Error Terms

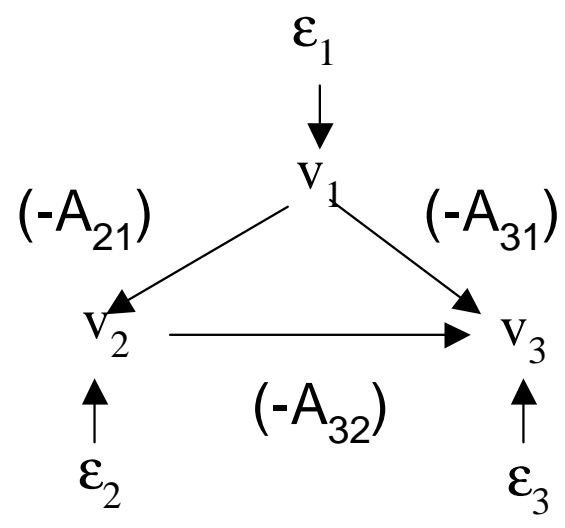

This DAG can be represented by the following recursive system:

$$
\begin{aligned}
& v_{1}(t)=\epsilon_{1}(t) \\
& v_{2}(t)=-A_{21} v_{1}(t)+\epsilon_{2}(t) \\
& v_{3}(t)=-A_{31} v_{1}(t)-A_{32} v_{2}(t)+\epsilon_{3}(t)
\end{aligned}
$$

where $\epsilon_{i}(t)$ are error terms $(i=1,2,3)$.

\footnotetext{
${ }^{19}$ Two linear-normal recursive Structural Equation Models are observationally equivalent if and only if they entail the same sets of zero partial correlations.
} 
The corresponding matrix $A_{0}$ is given by

$$
A_{0}=\left[\begin{array}{ccc}
1 & 0 & 0 \\
A_{21} & 1 & 0 \\
A_{31} & A_{32} & 1
\end{array}\right]
$$

where the necessary condition for identification is satisfied.

\subsection{Caveats of the Spirtes-Glymour-Scheines Methodology}

SGS have shown that under some weak conditions - the Markov Condition and Faithfulness - there exist methods for identification of causal relations that are asymptotically (in sample size) correct. The SGS claim that it is possible to make causal inferences based on associations observed in nonexperimental data without background knowledge came under fierce criticism. ${ }^{20}$

Using Bayesian methods, Robins and Wasserman (1999) showed that SGS implicitly admit that, for the set of studied variables, the probability of no unmeasured common causes is positive and not small relative to the sample size. If this is not true, then SGS analysis can lead to inappropriate causal conclusions. They claim that in studies with observational data, as those in economics and other areas, the assumption that this probability is small relative to the sample size, better reflects the position of researchers.

Robins et al. (2003) used classical methods to analyze carefully the asymptotic properties of SGS methodology. They showed that the asymptotically consistent procedures of SGS are pointwise consistent, but not uniform consistent. ${ }^{21}$ Furthermore, they also showed that there exists no causality test, based on associations of non-experimental data under the Markov and faithfulness assumptions, which is uniform consistent. Therefore, for any finite sample, it is impossible to guarantee that the results of the SGS causality tests (or any other causality test) will converge to the asymptotic results.

The difficulties of the SGS procedure can be illustrated using the recursive system of section 5.2.

In the recursive model, the parameter $A_{21}$ measures de direct effect of $v_{1}$ on $v_{2}, A_{32}$ the direct effect of $v_{2}$ on $v_{3}$ and $A_{31}$ the direct effect of $v_{1}$ on $v_{3}$. In the model $v_{2}$ is a direct cause of $v_{3}$ if and only if $A_{32} \neq 0$. In other words, in a causal graph of the model there is an arrow from $v_{2}$ to $v_{3}$ if and only if $A_{32} \neq 0$. If we know that the true causal effects are an unknown subset of the ones presented in figure 1 , the conditional independence of $v_{2}$ and $v_{3}$, under the other hypotheses of the model, can be straightfully tested by $H_{0}: A_{32}=0$ against $H_{1}: A_{32} \neq 0$.

Suppose we want to indirectly test, as in the SGS methodology, the conditional independence between $v_{2}$ and $v_{3}$ through the estimated sample covariance between them. If the $\operatorname{cov}\left(v_{2}, v_{3}\right)$ is exactly equal to zero, $\operatorname{cov}\left(v_{2}, v_{3}\right)=-A_{32}+A_{21} A_{31}=0$, then (considering the previous paragraph's assumption about the true causal effects) there are two possible causes for the zero correlation. One possibility is that $A_{32}$ and at least $A_{21}$ or $A_{31}$ are equal to zero. In this case, inferring that $v_{2}$ does not cause $v 3$, from the zero correlation, is correct. On the other hand, even if $A_{32}$ is large we can still obtain a zero correlation between $v_{2}$ and $v_{3}$ if $A_{32}=A_{21} A_{31}$. However, adopting faithfulness (the Faithfulness Condition adopted by the SGS methodology) we assume that no conditional independence relation is hidden by this unlikely combination of parameters, which have Lebesgue measure equal to zero (is very unlikely). A distribution for which $A_{32}=A_{21} A_{31}$ is unlikely and unfaithful to the DAG $\mathrm{G}$, representing this model, since it shows exactly zero correlation between two variables not because of missing arrows in the DAG but because parameters exactly canceling each other in the correlation,

\footnotetext{
${ }^{20}$ See for example, Humphreys and Freedman (1996, 1999), Korb and Wallace (1997), and Robins and Wasserman (1999).

${ }^{21} \mathrm{~A}$ pointwise consistent test is guaranteed to avoid incorrect decision if the sample size can be increased indefinitely. However, pointwise consistency is only a guarantee about what happens in the limit, not at any finite sample size. A stronger form of consistency, uniform consistency, guarantees that it is possible to bound the decisions error rates with a finite number of observations. See the Appendix for the definition of these concepts.
} 
$A_{32}=A_{21} A_{31}$. Under the SGS model, it is sufficient to have a sample $\operatorname{cov}\left(v_{2}, v_{3}\right)$ exactly equal to zero to deduce that $v_{2}$ is not a cause of $v_{3}$. However, if the sample correlation between $v_{2}$ and $v_{3}$ is not exactly zero (as will almost always happens in finite samples) and the true model is unknown, as Robins et al. (2003) have shown, the acceptance or rejection of the null hypothesis of zero partial correlation is not unequivocally tied to the presence of conditional independence. ${ }^{22}$ Without strong additional assumptions, there are no statistical tests based on correlations to determine that the causal effect is zero. This is true because Faithfulness has implications only for cases where the partial correlation is exactly zero (a unlikely case in finite samples). It does not rule out arbitrarily small partial correlations with the edge coefficient $\left(A_{32}\right)$ been arbitrarily large (not very unlikely in finite samples). Zhang (2002), Zhang and Spirtes (2003) proposed stronger versions of the faithfulness assumption that eliminate this latter possibility. Intuitively, these stronger assumptions say that small partial correlations indicate small direct causal effects. They show that these strengthened versions of faithfulness if true are sufficient to render the SGS model uniformly consistent.

In this article we assume that small partial correlations indicate small direct causal effects. This strong assumption is implicitly adopted in the procedures proposed by SGS.

\section{MONETARY POLICY DEVELOPMENTS SINCE THE REAL PLAN}

The Real Plan introduced several changes in the rules of monetary policy to achieve inflation stabilization. $^{23}$ The Provisional Measure (PM) no. 566 of July $29^{\text {th }}$ of 1994 , which implemented these changes, established quarterly limits for money expansion in the new currency, the real. ${ }^{24}$ Starting in the first quarter of 1995 the procedure of setting monetary limits was substituted for a monetary programming with quarterly projections for the expansion of monetary base (restricted and extended), M1, and M4 (the broadest monetary aggregate), formulated by the Central Bank and submitted to the Congress for evaluation, after approval by the National Monetary Council (CMN).

Although the new currency (the Real) was introduced at a rate of one-to-one to the U.S. dollar, there was no official commitment to any exchange rate policy. At first the Central Bank did not intervene in

\footnotetext{
${ }^{22}$ When the sample correlation is not exactly zero, it is not possible to determine which significance level should be used to test for zero partial correlation when attempting to test for conditional independence. The significance level cannot be interpreted as the probability of type I error for the pattern output, but merely as a parameter of the search. Based on simulation tests with random DAGs, SGS suggests setting the significance level at $20 \%$ for sample size smaller than 100 ; at $10 \%$ for sample size between 100 and 300; and at $0.5 \%$ (or smaller) for larger samples. We followed their suggestion and set the significance level at $20 \%$. We tested different levels of significance in the neighborhood of the chosen level (20\%) and noticed that the contemporaneous causality relationships assigned by TETRAD didn't changed.

${ }^{23}$ As source of information this section used Lopes (2003), several issues of the Boletim do Banco Central do Brasil for the period, the provisional measures cited in the text, Central Bank of Brazil (1999), the IMF Survey of November 16, 1998 and December 14,1998 , the Boletim Conjuntural IPEA of January 1999, as well as information contained in the homepage of the Central Bank of Brazil (www.bcb.gov.br).

${ }^{24}$ The ceilings for monetary base in the third and fourth quarters of 1994 were set at R\$ 7,5 billion and R\$ 8,5 billion, respectively. However, the same PM allowed the National Monetary Council (CMN) to authorize an extra margin of up to $20 \%$ of these limits. Neither the PM no. 566 nor the PM no. 596 (its update), defined how the monetary ceilings should be measured. This was set as responsibility of the CMN, who later chose the daily average balance concept. In the July-September quarter the monetary base - measured by average daily balances - reached R 8.9 billion, slightly below the R 9 billion ceiling once the $20 \%$ extra margin was approved by the CMN on August $24^{\text {th }}$ [the monetary base measured by end of period balances reached RS 12,8 billion at the end of the third quarter of 1994]. The monetary limit for the last quarter of 1994 was reviewed twice. The PM no. 681 of October $27^{\text {th }}$ of 1994 substituted the original limit of RS 8,5 billion substituted by a new limit that allowed an increase of $13.33 \%$ over the balances observed at the end of September, meaning that the new limit was $\mathrm{R} \$ 14,5$ billion. Then, on December $21^{\text {st }}$ the CMN approved a new ceiling of R\$ 15,1 billion. The average daily balance of the monetary base of the October-December quarter reached RS 14,8 billion. The Provisional Measure no. 681 also introduced the concept of extended monetary base together with the establishment of a zero growth rate for it during the last quarter of 1994 (the extended base adds federal government securities in the market (except LBC-E) to the traditional concept of monetary base). The CMN authorized on December $21^{\text {st }}$ a growth rate of $3.5 \%$ for the extended base, whose effective growth reached $1.9 \%$.
} 
the foreign currency market and the Real appreciated vis-à-vis the dollar. The Central Bank reports that it began intervening in the exchange rate market in the second half of September. ${ }^{25}$ On March $10^{\text {th }}$ of 1995 the Central Bank introduced a formal 0.88-0.93 exchange rate band with the commitment to intervene only on its limits, after an unsuccessful attempt to introduce a narrower band a day before when it lost 4 billion dollars in international reserves (see Figure 2). At the same time the SELIC interest rate was sharply increased in order to prevent any speculation against the Real (see Figure 3).

Figure 2 - International Reserves, from July 94 to February 1999 (note: the amounts pictured above include US\$ 9.3 billion received on December 1998 as part of the financial program coordinated by the IMF)

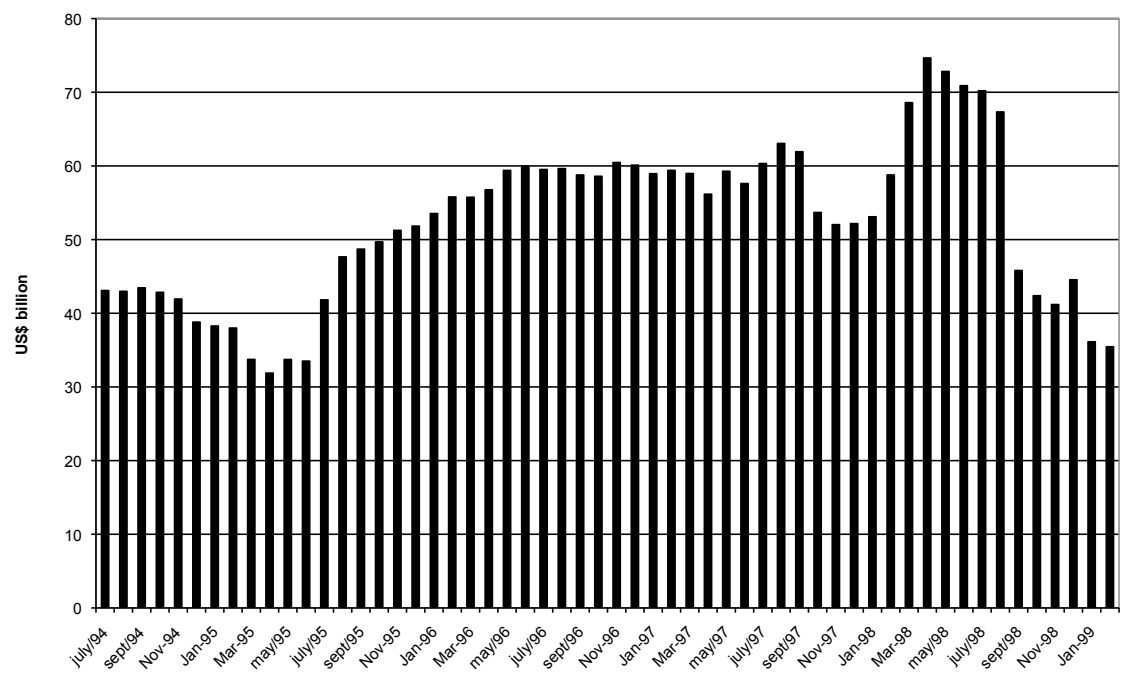

On June of 1995 a new 0.91-0.99 exchange rate band was announced together with the introduction of a new mechanism of intervention in the foreign exchange market, the "spread-auction", that in practice resulted in an exchange rate peg (see figure 4) through what became know as "mini-bands". ${ }^{26}$ There was no official rule for the speed of the crawling but it was understood that it was being set so as to slowly devaluate the Real.

On June $20^{\text {th }}$ of 1996 the Monetary Policy Committee (COPOM) was created with the objective of setting the stance of monetary policy and the short-term interest rate. The design of monetary policy operational procedure was modified with the introduction of two new interest rates - the TBC and the TBAN. ${ }^{27}$ According to Lopes (2003), in this setup inspired in the Deutsche Bundesbank the TBC, the rate at which banks could have financial assistance through rediscount window of the Central Bank, played the role of an interest rate floor, and the TBAN the ceiling. In principle, the SELIC rate would be allowed to fluctuate freely inside this interest rate band, with the values of both TBC and TBAN rates being determined by the COPOM. However, in practice the Central Bank managed to put the SELIC rate close to the $\mathrm{TBC}$ rate most of the time (see figure 5).

\footnotetext{
${ }^{25}$ See the Boletim do Banco Central do Brasil of November 1994.

${ }^{26}$ Notice that the "mini-bands" are not pictured in figure 5, only the "regular" bands.

${ }^{27}$ The TBC was created on July $1^{\text {st }}$ of 1996 and the TBAN on August $28^{\text {th }}$ of 1996.
} 
Figure 3 - SELIC Overnight Interest Rate, Annualized

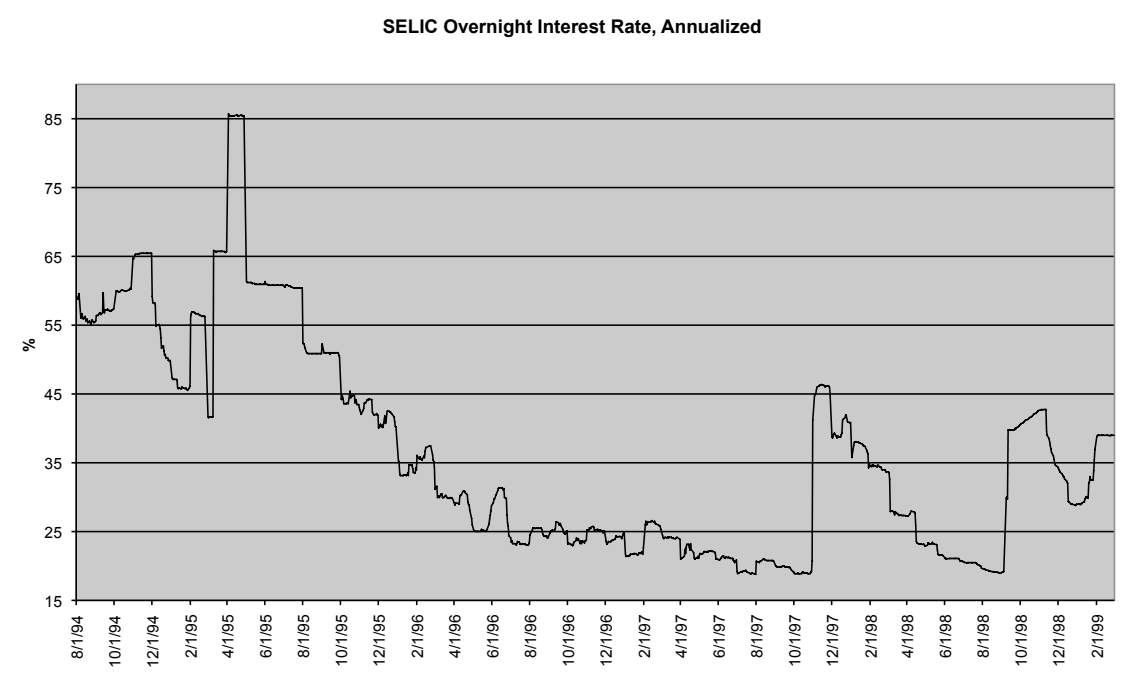

Figure 4 - Exchange Rate (R\$/US\$), from July 1994 to January 1999

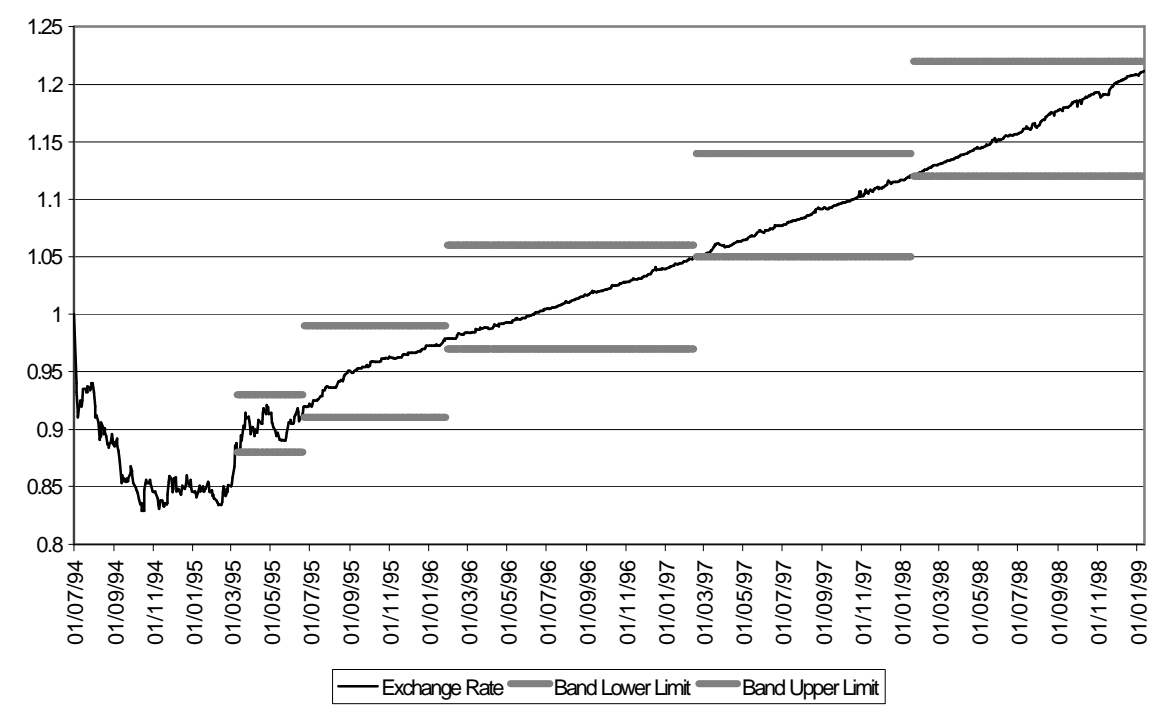


Figure 5 - Overnight Interest Rates, Annualized - from July 1996 to March 1999

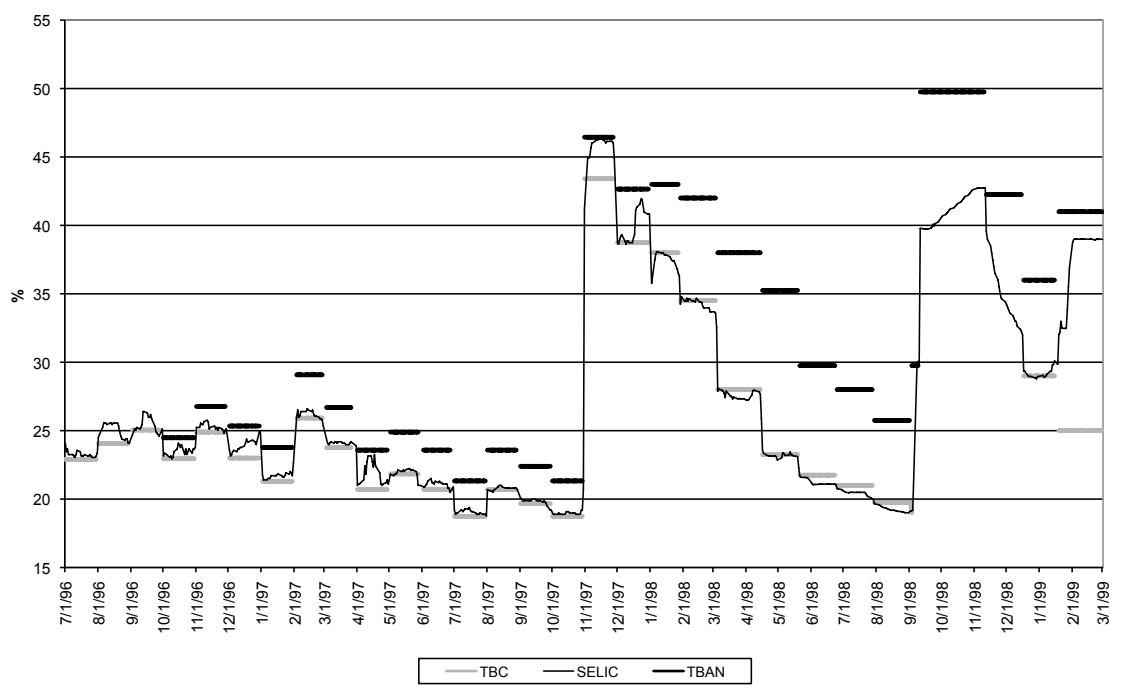

Note: the TBC rediscount window was closed from September 4th of 1998 to December 16th of 1998.

The Asian Crisis ${ }^{28}$ and the Russian default ${ }^{29}$ affected Brazil through the loss of international reserves, which caused sharp interest rate increases on October 1997 and September 1998. The monetary policy during these periods was dominated by the Brazilian government attempt to defend the real. On September $4^{\text {th }}$, 1998 there was a change in the operational procedure of the Central Bank: the rediscount window at the TBC rate was closed, making the SELIC rate jump to the TBAN rate. Despite the government's efforts, the international reserves kept sliding. On November $13^{\text {th }}, 1998$ Brazil and the International Monetary Fund (IMF) announced the conclusion of negotiations on a financial program that provided support of U\$ 41.5 billion over the next three years, making U\$ 37 billion available, if needed, over the next 12 months. The Central Bank gave up defending the exchange rate on January $15^{\text {th }}, 1999$ and announced the free-floating as the new exchange rate regime on January $18^{\text {th }}, 1999$.

On March $4^{\text {th }}$ of 1999 both TBC and TBAN rates were extinguished and a new monetary policy operational procedure was introduced. In this new framework the COPOM sets a target for the SELIC rate that remains constant until the next regular COPOM meetings. However, the COPOM could establish a monetary policy bias at its regular meetings; a bias (to ease or tighten) authorizes the Central Bank's Governor to alter the SELIC interest rate target in the direction of the bias anytime between regular

${ }^{28}$ In the wake of the Asian Crisis Brazil lost near $15 \%$ of its foreign reserves on October $28^{\text {th }}$ of 1997 (see figure 3). In response, the Central Bank increased sharply interest rates with the SELIC overnight rate reaching more than $45 \%$ per annum (it was near $20 \%$ before, see figure 6) and started to operate in the dollar futures market in order to defend the exchange rate. Despite the negative effect of the interest rate hike over the public debt, it induced a huge increase in international reserves, which moved from US\$ 52 billion in November 1997 to near US\$ 75 billion in April 1998 (see figure 3).

${ }^{29}$ On August $17^{\text {th }}$ of 1998 , the rouble devaluation and the Russian default provoked an international financial crisis. According to Lopes, the Central Bank responded increasing interest rates in four stages (see figure 6). First, on September $2^{\text {nd }}$, the TBAN rate was increased from $25.75 \%$ to $29.75 \%$ per annum. In the second stage, on September $4^{\text {th }}$, the rediscount window at the TBC rate was closed, making the SELIC rate jump to the TBAN rate. In the third stage, on September $4^{\text {th }}$, the TBAN rate was increased to $49.75 \%$. In the last stage, the SELIC rate was gradually increased through open market operations, reaching $42.75 \%$ on November $4^{\text {th }}$. 
COPOM meetings. As can be seen in figure 6, in this new monetary policy framework the SELIC rate hits its target value as the Central Bank offsets total reserve demand and borrowing demand disturbances. ${ }^{30}$ Brazil implemented a formal inflation targeting framework for monetary policy on June 21 of 1999. Under the inflation targeting regime, the COPOM's monetary policy decisions have as their main objective the achievement of the inflation targets set by the National Monetary Council (CMN). If inflation breaches the target set by the CMN, the Governor of the Central Bank is required to write an open letter to the Minister of Finance explaining the reasons why the target was missed, as well as the measures required to bring inflation back to the target, and the time period over which these measures are expected to take effect. The introduction of inflation targeting didn't change the monetary policy operational procedure, which continued to be based on the control of the SELIC rate (see Figure 6).

Figure 6 - Comparison between the Target for the SELIC Rate Determined by the Central Bank and the Effective SELIC Rate

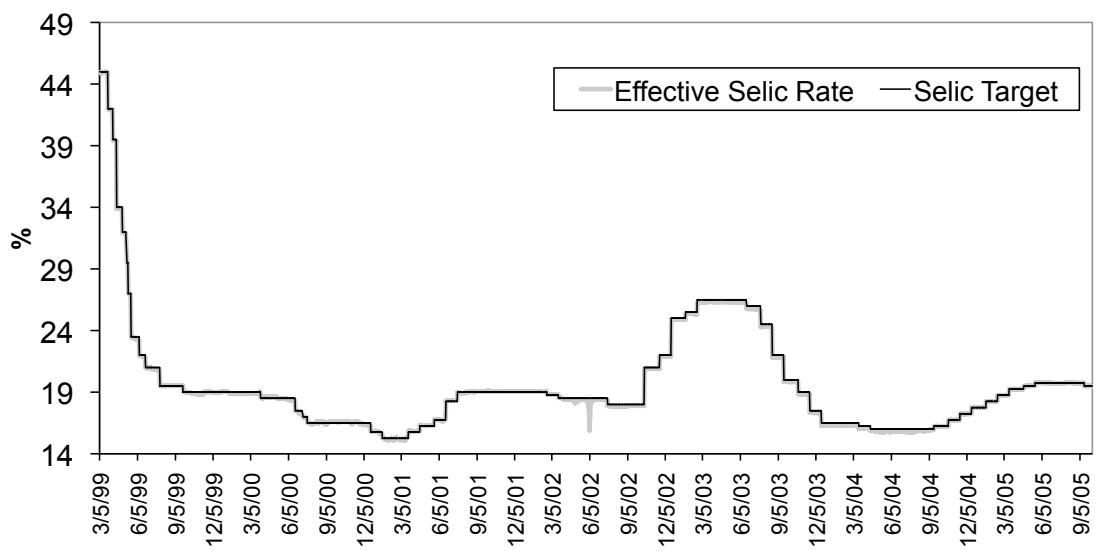

As seen above, Brazil experienced several changes in policy regime in the period after the Real Plan. Therefore, in order to appropriately conduct an empirical analysis of this period it is important to divide it in subsamples sharing common features. Unfortunately, some of these subsamples are too short to allow for any type of econometric analysis. Based on the exchange rate regime and monetary policy operational procedures, we decided to partition our sample into two subsamples. The first one goes from 1996:07 to 1998:08, the period with exchange rate "mini-bands" combined with the adoption of the TBC rate as an informal target for the SELIC rate. The second one goes from 1999:03 to 2004:12, the period with free-floating exchange rate and explicit SELIC targeting.

\section{BASIC MODEL AND RESULTS FOR THE FIRST SUBSAMPLE (1996:07-1998:08)}

The variables selected for the Basic Model of the first subsample (BM1) are: SELIC, international reserves, price level, money (M1), output, a constant, and seasonal dummies. Given the small sample

\footnotetext{
${ }^{30}$ During the second and third quarters of 2002 the Central Bank had difficulties in hitting its SELIC target because of the decline in the demand for public securities due to the migration of resources out of Financial Investment Funds (FIF) into other modalities of financial investment caused by the requirement of the marking-to-market methodology in pricing fund assets.
} 
size, we restricted the analysis to lag length one, which is also the lag order selected by the Schwarz Information Criterion (SIC).

\subsection{Contemporaneous Causal Ordering}

Applying TETRAD at the $20 \%$ significance level ${ }^{31}$ and assuming that the variables selected for the model are causally sufficient ${ }^{32}$, we obtain what is known as a pattern, ${ }^{33}$ shown in Figure 7 . The pattern is a graphical representation of the set of observationally equivalent DAGs containing the contemporaneous causal ordering of the variables. According to Figure 7 the BM1 has four observationally equivalent DAGs, displayed on figure 8. Each of these DAGs is a valid representation of the contemporaneous causal ordering of the BM1 according to TETRAD. In what follows we will restrict our attention to the causal ordering displayed on figure 8(b), but we would like to stress that the results discussed next do not change much when the alternative causal orderings are used. According to figure $8(\mathrm{~b})$, neither the SELIC rate nor the stock of money (M1) are contemporaneously affected by the other variables of the model, with international reserves responding to changes in the SELIC rate within the same period, suggesting the level of reserves is sensible to interest rate differentials. ${ }^{34}$ In addition, changes in output have immediate effect on prices $^{35}$

Figure 7 - Pattern of the BM1

SELIC

M1

\section{RESERVES}

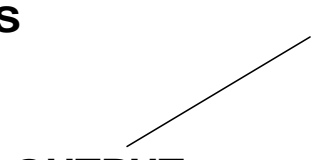

IPCA

\subsection{Impulse Response Analysis}

Using the contemporaneous causal ordering of figure 8(b) to identify the BM1, we compute and analyze in this section the impulse response functions of economic variables to exogenous and independent shocks. ${ }^{36}$

\footnotetext{
${ }^{31}$ See Footnote 22.

${ }^{32} \mathrm{~A}$ set of variables $\mathrm{V}$ is said to be causally sufficient if every common cause of any two or more variables in $\mathrm{V}$ is in V. TETRAD has a bias towards excluding causal relations present in the data. To overcome this problem, SGS suggests that a $20 \%$ significance level should be used.

${ }^{33}$ A pattern is a partially oriented DAG, where the directed edges represent arrows that are common to every member in the equivalent class, while the undirected edges are directed one way in some DAGs and another way in others. Undirected edges $(-)$ mean that there is causality in one of the two directions but not on both, while double oriented edges $(\leftrightarrow$ ) mean causality on both directions.

${ }^{34}$ Notice that this result stands against the assumption made by Fernandes and Toro (2005) that international reserves are an exogenous variable.

${ }^{35}$ We estimated an alternative model with the same variables of the BM1 using a different subsample that starts at 1995:05 and ends at 1998:12. We noticed that TETRAD's identification of the contemporaneous causal ordering showed some sensibility to whether the IMF loan of US\$ 9.3 billion given to Brazil on December of 1998 was included or not. The exclusion of the loan led to the exclusion also of the edge between SELIC and reserves in the respective pattern.

${ }^{36}$ We will not present and discuss the parameters estimates of the model because of the difficulties associated with their interpretation, specially the estimates of the central bank reaction function. See Christiano et al. (1999) for a discussion of the pitfalls in interpreting estimated monetary policy rules.
} 
Figure 8 - Observationally Equivalent DAGs from the Pattern of the BM1

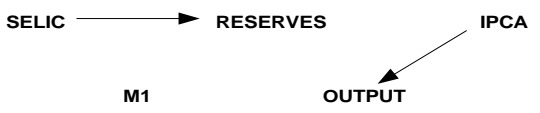

Figure 8 (a)
RESERVES

M1

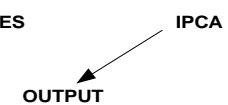

Figure 8 (c)

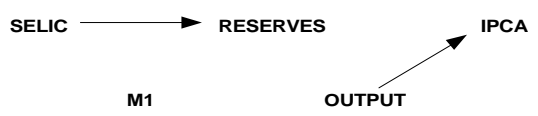

Figure 8 (b)

SELIC

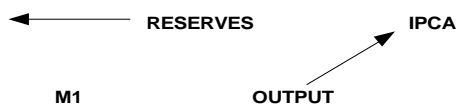

Figure $8(d)$

The impulse response functions (IRFs) displayed on figure $9^{37}$ show that output and money fall in response to a positive SELIC shock. ${ }^{38}$ The large uncertainty of the response of the price level to a SELIC shock (reflected in large probability bands) is not surprising, due to the small sample size, and indicates that we should be cautious when inferring what is the response of the price level to a SELIC shock. However, the most likely result (indicated by the solid line between the bands) is that the price level goes down in response to a SELIC innovation. ${ }^{39}$ Positive money shocks on the other side have a more immediate effect over prices but no significant effect on the SELIC rate. Positive international reserves shocks decrease interest rates and stimulate economic activity, leading to an increase in inflation. The results for this period suggest that SELIC shocks are the best candidates for representing monetary policy shocks.

\section{BASIC MODEL AND RESULTS FOR THE SECOND SUBSAMPLE (1999:03-2004:12)}

The variables selected for Basic Model of the second subsample (BM2) are not all the same as those chosen for the Basic Model of the first subperiod (BM1). The differences are that we substituted the exchange rate for the international reserves, given that now there is free floating of the exchange rate, and substituted the medium term interest rate (SWAP) for money because the Central Bank started targeting (explicitly) the short-run interest rate. Therefore, the BM2 is composed by: SELIC, exchange rate, price level, SWAP, output, a constant, and seasonal dummies. The chosen lag length of the BM2 is one, following the Schwarz information criterion (SIC).

\subsection{Contemporaneous Causal Ordering}

Using TETRAD to find out the contemporaneous causal ordering of the BM2, ${ }^{40}$ we obtain the pattern displayed on figure 10, containing just one DAG, used to identify the BM2.

According to the identification suggested by TETRAD, SELIC shocks affect output and the SWAP rate contemporaneously. This result is a departure from the widely used identification assumption that the variables in the Central Bank information set do not respond to monetary policy shocks within the

\footnotetext{
${ }^{37}$ The error bands for impulse responses were constructed following the methodology suggested bySims and Zha (1999).

${ }^{38}$ By "positive" SELIC shock we mean an unexpected increase in the SELIC rate. This type of shock is also referred in the literature as "contractionary" because it is supposed to contract economic activity.

${ }^{39}$ In an alternative model for the 1995:05-1998:12 subperiod, where the exchange rate and the SWAP rate were used instead of international reserves and M1, we observed an increase in the price level in response to a SELIC shock, without taking into account the uncertainty of the period.

${ }^{40}$ See footnote 22 .
} 
Figure 9 - Observationally Equivalent DAGs from the Pattern of the BM1

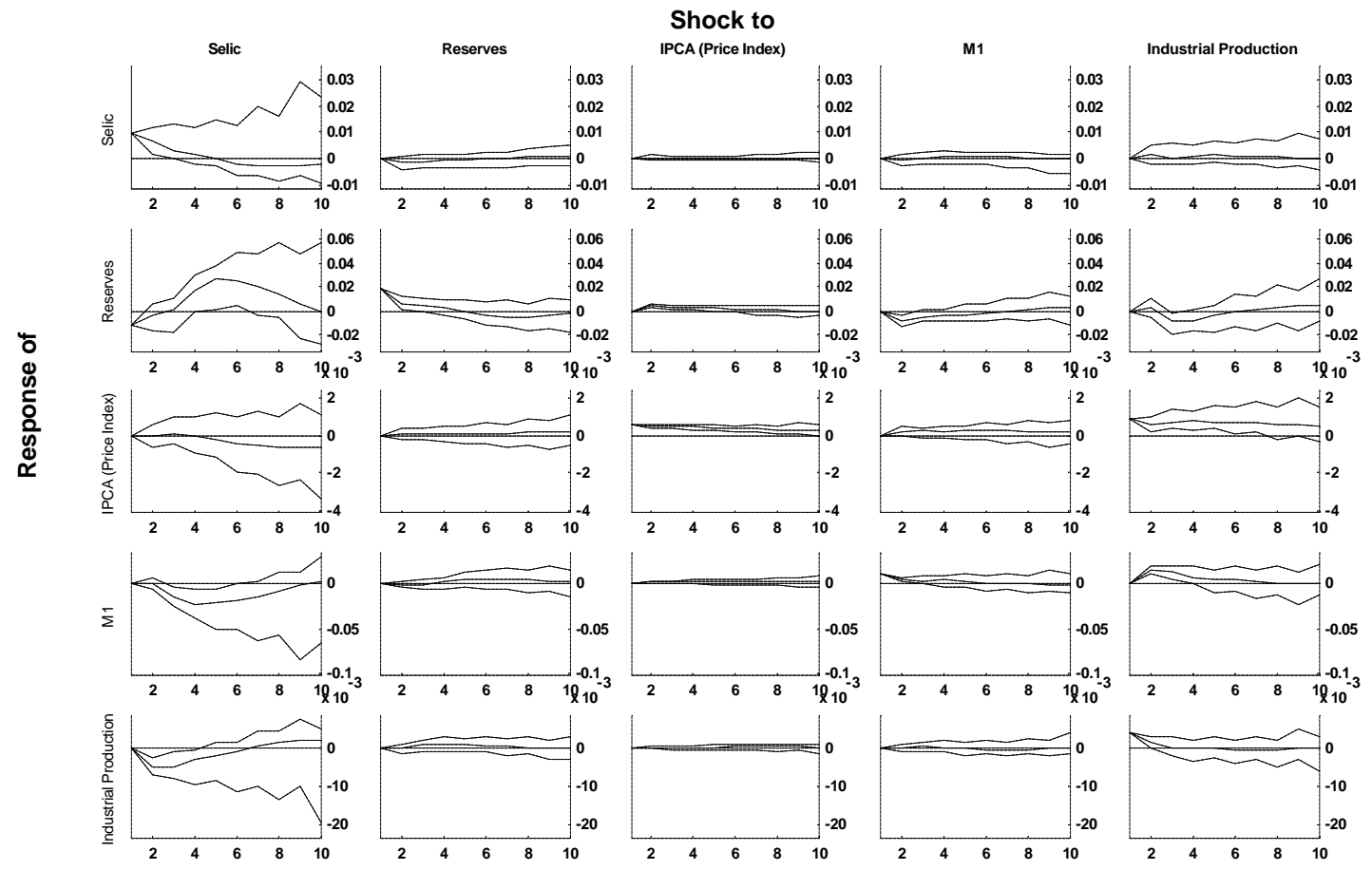

Figure 10 - Pattern of the BM2

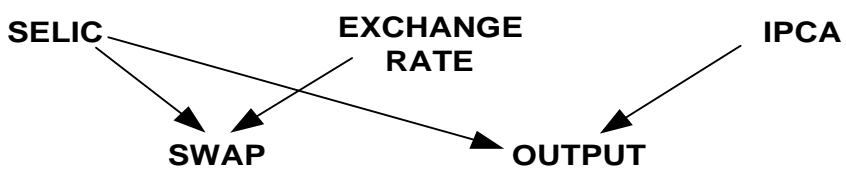

current period. ${ }^{41}$ Additionally, we observe that in TETRAD's identification, none of the variables affect contemporaneously the SELIC rate, even the price level and the output. The fact that output and prices have no contemporaneous effect over the SELIC rate may be associated with the difficulty of obtaining information on the current level of output and price level by the time policy makers have to make their decisions, an assumption made, for example, by Sims and Zha (2006).

\footnotetext{
${ }^{41}$ Christiano et al. (1999) refer to this assumption as the recursiveness assumption. It implies that economic variables within the period are determined in a block recursive way: first, the variables of the goods market are determined; second the Central Bank sets its instrument; and third, the remaining variables are determined. Examples of such identification strategy are Christiano et al. (1996), and Bernanke and Mihov (1998). However, although there are models consistent with the recursiveness assumption, it is controversial and that is why some authors like Sims and Zha (2006) and Leeper and Roush (2003) employ an alternative approach.
} 


\subsection{Impulse Response Analysis and Variance Decomposition}

Using the contemporaneous causal ordering of figure 10 to identify the BM2 we obtained the IRFs displayed on Figure 11.

Figure 11 - IRFs of the Benchmark Model 1999:03 - 2004:12, with 68\% Probability Bands (lag = 1)
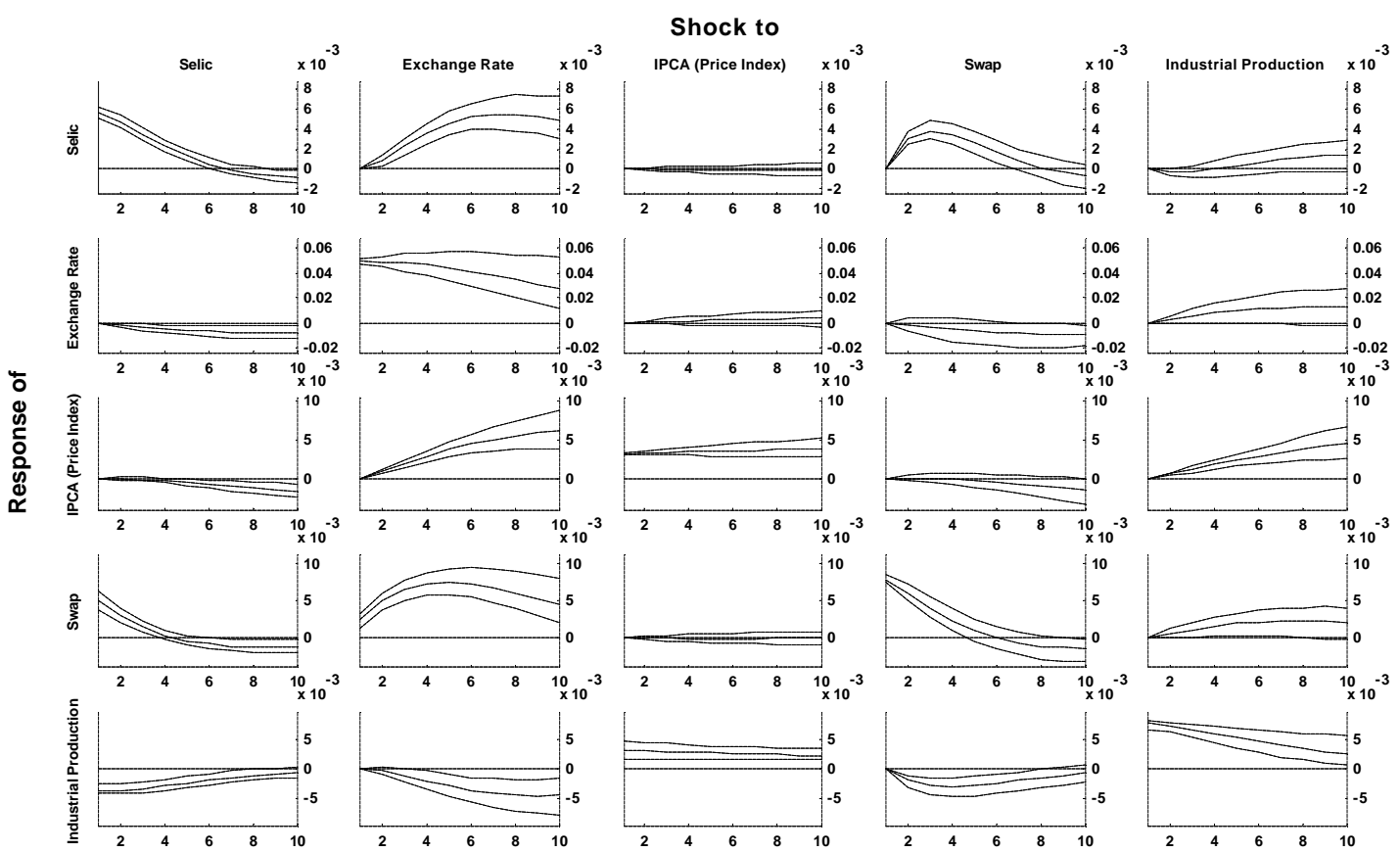

As can be seen in Figure 11, the responses to a positive SELIC innovation are in line with the results that one would expect from (contractionary) monetary policy shocks: the exchange rate appreciates, output decreases, and the price level goes down. It is interesting to note the lag with which the price level responds to a (positive) SELIC shock: it takes near six months until the price level starts to fall despite the immediate and persistent contraction of economic activity, that returns to its pre-shock level after one year.

Using the same structural decomposition of the IRFs to calculate the variance decomposition, we observe that a substantial portion of the forecast error variance of the SELIC rate can be attributed to exchange rate shocks, about $61 \%$ after twelve months, with Swap shocks responding to $13 \%$, while output and price level shocks represent 3-5\% and 0.02\%, respectively (see Table 1).

Unexpected exchange rate devaluations are inflationary with the price level starting to increase one month after the exchange rate shock hits the economy. In fact, exogenous shocks to the exchange rate are for the 1999-2004 period, the most important exogenous source of inflation rate fluctuation, as can be seen more clearly in the variance decomposition of the price level, displayed on table 2 . With 12 months ahead, the exchange rate shock is responsible for near $45 \%$ of forecast error variance of the price level. Despite the persistence of the (positive) exchange rate shock, the resulting increase in inflation and in interest rates imply that there is a contraction in the level of economic activity.

The increase in the price level in response to positive output shocks suggests that they are associated with demand shocks. This inflationary effect explains why interest rates goes up in response to (positive) output shocks in the second subsample. 
Table 1 - Variance Decomposition of SELIC

\begin{tabular}{|c|c|c|c|c|c|c|}
\hline Period & S.E. & Selic Shock & $\begin{array}{c}\text { Exchange } \\
\text { Rate Shock }\end{array}$ & IPCA Shock & $\begin{array}{c}\text { Swap Shock } \\
\text { Shock }\end{array}$ & Output \\
\hline 1 & 0.006504 & 1.000 .000 & 0.000000 & 0.000000 & 0.000000 & 0.000000 \\
2 & 0.009226 & 8.419 .765 & 1.090 .360 & 0.000215 & 1.447 .120 & 0.240568 \\
3 & 0.011275 & 6.908 .451 & 5.918 .915 & 0.003608 & 2.471 .916 & 0.273804 \\
4 & 0.012908 & 5.695 .910 & 1.470 .535 & 0.011013 & 2.811 .397 & 0.210569 \\
5 & 0.014352 & 4.716 .222 & 2.560 .766 & 0.019887 & 2.697 .736 & 0.232886 \\
6 & 0.015724 & 3.942 .947 & 3.621 .287 & 0.027274 & 2.390 .226 & 0.428127 \\
7 & 0.017036 & 3.359 .299 & 4.494 .470 & 0.031778 & 2.064 .566 & 0.784878 \\
8 & 0.018252 & 2.935 .975 & 5.136 .890 & 0.033568 & 1.799 .126 & 1.246 .526 \\
9 & 0.019331 & 2.636 .984 & 5.574 .450 & 0.033499 & 1.609 .633 & 1.755 .829 \\
10 & 0.020249 & 2.429 .200 & 5.855 .154 & 0.032450 & 1.485 .295 & 2.271 .059 \\
11 & 0.021000 & 2.286 .453 & 6.024 .696 & 0.031064 & 1.409 .177 & 2.765 .680 \\
12 & 0.021592 & 2.189 .538 & 6.118 .989 & 0.029723 & 1.366 .126 & 3.223 .747 \\
13 & 0.022043 & 2.124 .776 & 6.164 .110 & 0.028611 & 1.344 .654 & 3.635 .988 \\
14 & 0.022376 & 2.082 .473 & 6.178 .363 & 0.027778 & 1.336 .646 & 3.997 .398 \\
15 & 0.022613 & 2.055 .719 & 6.174 .399 & 0.027198 & 1.336 .564 & 4.305 .972 \\
16 & 0.022776 & 2.039 .546 & 6.160 .856 & 0.026815 & 1.340 .710 & 4.562 .058 \\
17 & 0.022884 & 2.030 .362 & 6.143 .518 & 0.026567 & 1.346 .668 & 4.767 .955 \\
18 & 0.022953 & 2.025 .575 & 6.126 .118 & 0.026408 & 1.352 .908 & 4.927 .580 \\
19 & 0.022995 & 2.023 .344 & 6.110 .892 & 0.026317 & 1.358 .524 & 5.046 .090 \\
20 & 0.023021 & 2.022 .393 & 6.098 .994 & 0.026300 & 1.363 .036 & 5.129 .468 \\
21 & 0.023036 & 2.021 .884 & 6.090 .808 & 0.026387 & 1.366 .262 & 5.184 .077 \\
22 & 0.023047 & 2.021 .303 & 6.086 .195 & 0.026626 & 1.368 .215 & 5.216 .248 \\
23 & 0.023056 & 2.020 .377 & 6.084 .693 & 0.027075 & 1.369 .030 & 5.231 .920 \\
24 & 0.023065 & 2.019 .005 & 6.085 .674 & 0.027796 & 1.368 .905 & 5.236 .377 \\
\hline & & & & & & \\
& & & & & \\
& & & & &
\end{tabular}

\subsection{Robustness of the Basic Analysis}

In this section we analyze the robustness of the results of the Basic Model of the second subperiod (BM2) to two changes in the original model. First, we consider the effects of different lag lengths of the VAR model. Second, we analyze the consequences of introducing money in the basic model.

\subsubsection{Different Lag Lengths}

We estimated alternative models using the same variables of the basic model employing different lag lengths. ${ }^{42}$ Figures 12 and 13 show the contemporaneous causal orderings provided by TETRAD for lag lengths 2 and 3, respectively, used to identify the IRFs. ${ }^{43}$ Notice that TETRAD provides different orderings for each lag length as a result of differences in the estimated covariance matrices. Despite the differences in identification, the qualitative features of these IRFs, displayed on Figures 14 and 15, aren't much different from those of the BM2 (Figure 11), with the exception the response of the price level to monetary policy shocks. For lags 2 and 3 the price level temporarily increases in response to a

\footnotetext{
${ }^{42}$ Starting with lag length three, the residuals exhibit no autocorrelation. For this reason, here we restrict our analysis to lag lengths up to three.

${ }^{43}$ Undirected edges $(-)$ mean that there is causality in one of the two directions but not on both. In what follows we will consider the causal ordering running from output to IPCA, but the results do not change much if the alternative ordering is used instead.
} 
Table 2 - Variance Decomposition of SELIC

\begin{tabular}{|c|c|c|c|c|c|c|}
\hline Period & S.E. & Selic Shock & $\begin{array}{c}\text { Exchange } \\
\text { Rate Shock }\end{array}$ & IPCA Shock & $\begin{array}{c}\text { Swap Shock } \\
\text { Shock }\end{array}$ & Output \\
\hline 1 & 0.003684 & 0.000000 & 0.000000 & 1.000 .000 & 0.000000 & 0.000000 \\
2 & 0.005464 & $7.51 \mathrm{E}-05$ & 4.483 .900 & 9.376 .522 & 0.047765 & 1.703 .042 \\
3 & 0.007235 & 0.034697 & 1.260 .252 & 8.255 .653 & 0.056090 & 4.750 .162 \\
4 & 0.009169 & 0.167297 & 2.130 .117 & 7.039 .988 & 0.035071 & 8.096 .585 \\
5 & 0.011284 & 0.408009 & 2.878 .560 & 5.958 .524 & 0.052434 & 1.116 .871 \\
6 & 0.013545 & 0.727680 & 3.451 .450 & 5.080 .783 & 0.151405 & 1.379 .859 \\
7 & 0.015906 & 1.089 .467 & 3.859 .085 & 4.397 .008 & 0.337753 & 1.601 .185 \\
8 & 0.018314 & 1.464 .072 & 4.132 .357 & 3.872 .601 & 0.595655 & 1.789 .070 \\
9 & 0.020728 & 1.832 .368 & 4.303 .080 & 3.471 .734 & 0.902640 & 1.951 .685 \\
10 & 0.023110 & 2.183 .384 & 4.397 .761 & 3.164 .632 & 1.237 .500 & 2.095 .518 \\
11 & 0.025433 & 2.511 .616 & 4.436 .817 & 2.928 .425 & 1.583 .150 & 2.225 .281 \\
12 & 0.027677 & 2.814 .899 & 4.435 .496 & 2.746 .066 & 1.926 .977 & 2.344 .251 \\
13 & 0.029827 & 3.092 .982 & 4.405 .075 & 2.604 .950 & 2.260 .232 & 2.454 .654 \\
14 & 0.031877 & 3.346 .644 & 4.353 .905 & 2.495 .733 & 2.577 .186 & 2.557 .979 \\
15 & 0.033821 & 3.577 .175 & 4.288 .204 & 2.411 .431 & 2.874 .352 & 2.655 .213 \\
16 & 0.035660 & 3.786 .081 & 4.212 .634 & 2.346 .767 & 3.149 .854 & 2.747 .005 \\
17 & 0.037395 & 3.974 .933 & 4.130 .716 & 2.297 .706 & 3.402 .958 & 2.833 .789 \\
18 & 0.039031 & 4.145 .282 & 4.045 .118 & 2.261 .122 & 3.633 .721 & 2.915 .860 \\
19 & 0.040573 & 4.298 .623 & 3.957 .866 & 2.234 .567 & 3.842 .745 & 2.993 .430 \\
20 & 0.042025 & 4.436 .380 & 3.870 .493 & 2.216 .103 & 4.030 .990 & 3.066 .667 \\
21 & 0.043396 & 4.559 .903 & 3.784 .149 & 2.204 .176 & 4.199 .656 & 3.135 .719 \\
22 & 0.044690 & 4.670 .465 & 3.699 .682 & 2.197 .534 & 4.350 .081 & 3.200 .729 \\
23 & 0.045915 & 4.769 .265 & 3.617 .704 & 2.195 .157 & 4.483 .676 & 3.261 .845 \\
24 & 0.047077 & 4.857 .431 & 3.538 .637 & 2.196 .211 & 4.601 .875 & 3.319 .221 \\
\hline
\end{tabular}

positive SELIC shock, a result known in the literature as the "price puzzle", since it is at odds with most theoretical models' prediction that restrictive monetary policy should reduce the price level.

Figure 12 - Pattern of the Benchmark Model with Lag Length 2

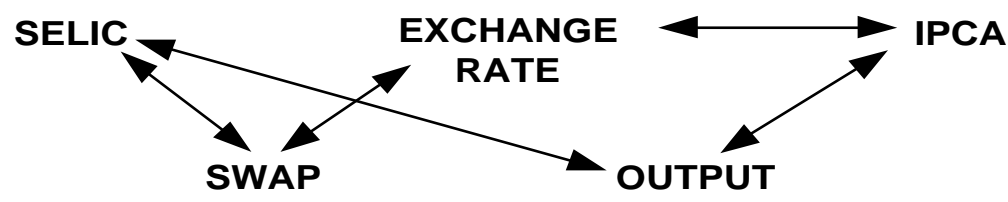


Figure 13 - Pattern of the Benchmark Model with Lag Length 3

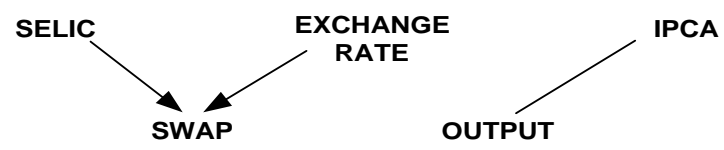

Observationally equivalent DAGs from the pattern of the figure 13

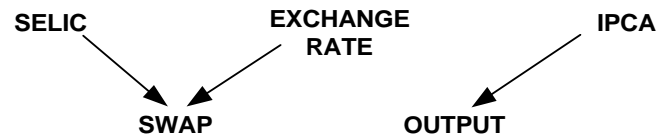

Figure 13 (a)

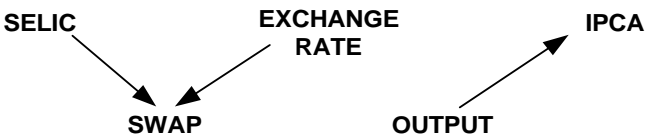

Figure 13 (b) 
Figure 14 - IRFs of the Model 1999:03 - 2004:12, with 68\% Probability Bands (lags = 2)
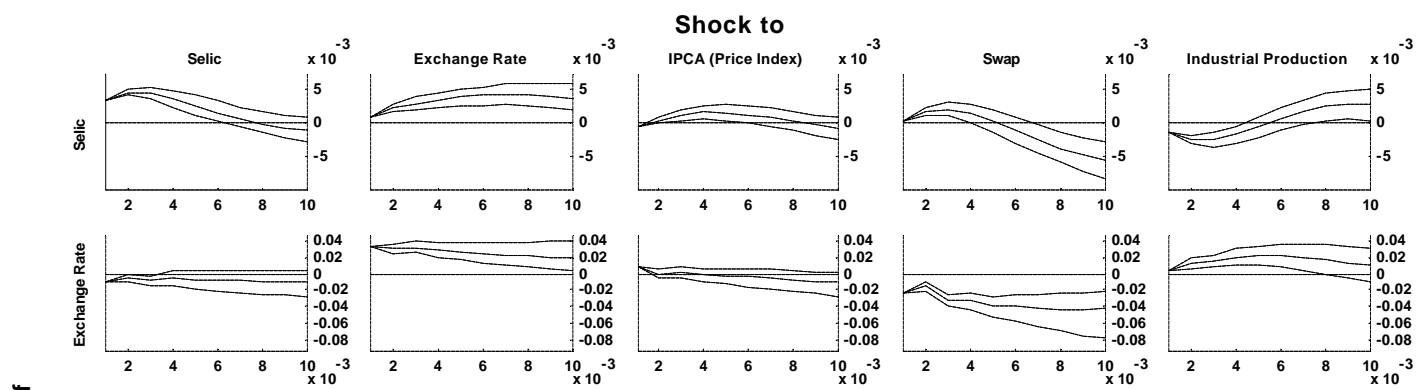

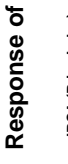
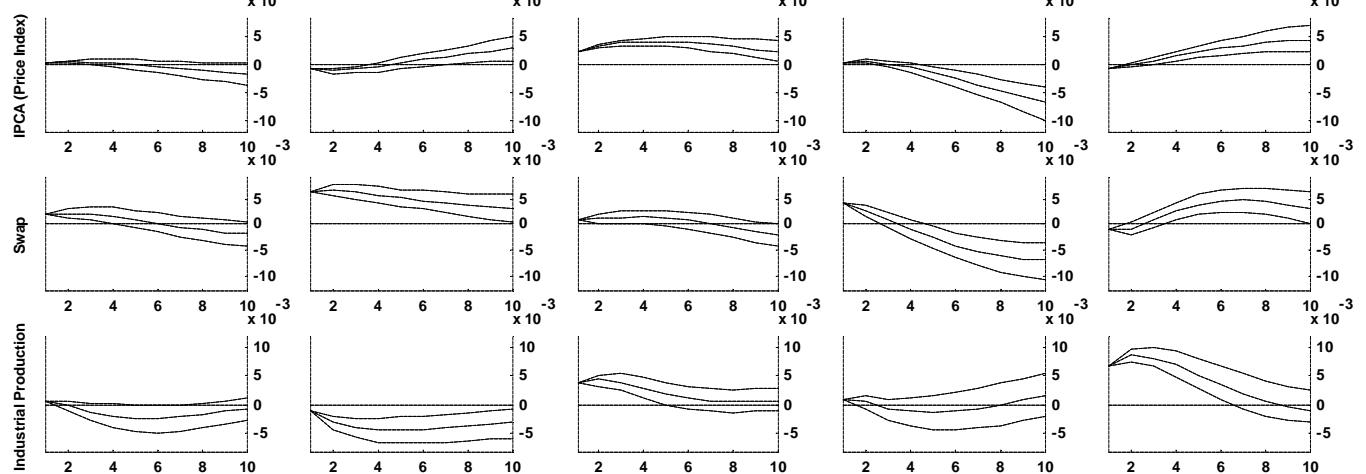
We offer four possible explanations for the appearance of the price puzzle for larger lag lengths:

(i) Failure to identify monetary policy shocks for larger lag lengths. Some authors (e.g. Sims (1998), Christiano et al. (1999)) have argued that the presence of the price puzzle should serve as an informal specification test of a VAR model: if such anomalous result is observed, then what one has labeled "monetary policy" probably has not been correctly identified. Identification schemes that combine a priori knowledge with TETRAD are able to fix the price puzzle. For lag length 2 , assuming that monetary policy cannot respond contemporaneously to disturbances in output due to the absence of contemporary data of output at the time policy decisions have to be made, ${ }^{44}$ and then running TETRAD (see Figure 16), provides an identification whose IRFs exhibit no price puzzle (see Figure 17); ${ }^{45}$

(ii) Overfitting. Given the small sample size, larger lag lengths imply a loss of degrees of freedom that results in inefficient estimates of the parameters and of the IRFs;

(iii) Omission of an (some) important variable(s). Sims (1992) suggested that the price puzzle might emerge in models that do not specify correctly the information available to the central bank. If policymakers observe variables that forecast inflation but these variables are not included in the model, there will be apparently unpredictable changes in interest rates that are actually systematic responses to expected inflation. In order to investigate this possibility, we extended the basic model by adding the market's inflation expectations, reported by the Focus survey of the Central Bank. ${ }^{46}$ As can be seen in figure 19, the introduction of inflation expectations didn't solved the price puzzle. In addition, according to Block-Exogeneity tests conducted, inflation expectations measured by the Focus survey are not (linear) informative about the future price level and the future SELIC rate. These results reinforce the main conclusion of Céspedes and Lima (2003) that given the poor ability of the Focus survey to forecast future inflation, it is unlikely that the Central Bank takes into account the Focus expected inflation when setting the SELIC rate;

(iv) The price puzzle may not be a puzzle at all. Barth and Ramey (2001) argue that a temporary price puzzle may not be an enigma once one takes into account the possibility that the monetary transmission mechanism itself has cost effects. Prices should go up in the short-run following an unanticipated monetary contraction if the cost effects of the monetary transmission mechanism dominate the demand effects. Christiano et al. (2005) developed a model with the cost channel that (in conjunction with other assumptions) accounts quantitatively for a positive initial price response to a monetary policy shock.

\subsubsection{Alternative Model: Including Money}

In this section we shall test whether the introduction of a broad monetary aggregate (M1) in our VAR model of the second subperiod matters for inferences about the impacts of monetary policy. In particular, we would like to check if the inclusion of money, in the VAR model, could fix the price puzzle that appears in the Basic Model for larger lag lengths.

\footnotetext{
${ }^{44}$ This assumption is part of the identifying restrictions made, for example, by Sims (1986).

${ }^{45} \mathrm{An}$ alternative identification that also fixes the price puzzle for lag length two is provided by the identification of the Basic Model (Figure 10). However, none of the identifications that we tried solved the price puzzle for lag length three.

${ }^{46}$ We used each month the Top Five average expected inflation (IPCA) accumulated over the next twelve months, collected one day after the inflation of the previous month became available. The survey started on November 2001, meaning that our sample size for this model is smaller, going from 2001:11 to 2004:12.
} 
Extending the basic model so as to include M1 as an additional variable and applying TETRAD at the $20 \%$ significance level, we obtained the patterns for lag lengths $1-3$, displayed on figures 20 22 , respectively. ${ }^{47}$ Using the contemporaneous causal orderings contained on the patterns to identify the corresponding alternative model with money, we obtained the IRFs presented on figures 23-25. ${ }^{48}$ The positive response of interest rates to expansionary money innovations suggests that M1 shocks should not be interpreted as monetary policy shocks, otherwise we would have the liquidity puzzle. ${ }^{49}$ Therefore, it seems that M1 shocks are better interpreted as money demand shocks rather than money supply shocks. Analyzing the IRFs of SELIC shocks of the model with money, we observe that they are qualitatively very similar to those of the basic model, meaning that the previous interpretation of the results goes through, only that now there is no initial price increase in response to a positive monetary policy innovation, even for larger lags.

\footnotetext{
${ }^{47}$ As happened with the basic model of the second subperiod, we restrict our analysis to lag lengths up to three, since the residuals exhibit no autocorrelation at lag 3.

${ }^{48} \mathrm{~A}$ word of caution: the comparison between the models with and without money depend not only on the addition of the new variable (M1), but also on the identification selected, that of course cannot be the same for both models.

${ }^{49}$ The liquidity puzzle happens when innovations in monetary aggregates, identified as monetary policy shocks, are associated with increases (rather than decreases) in nominal interest rates.
} 
Figure 15 - IRFs of the Model 1999:03 - 2004:12, with 68\% Probability Bands

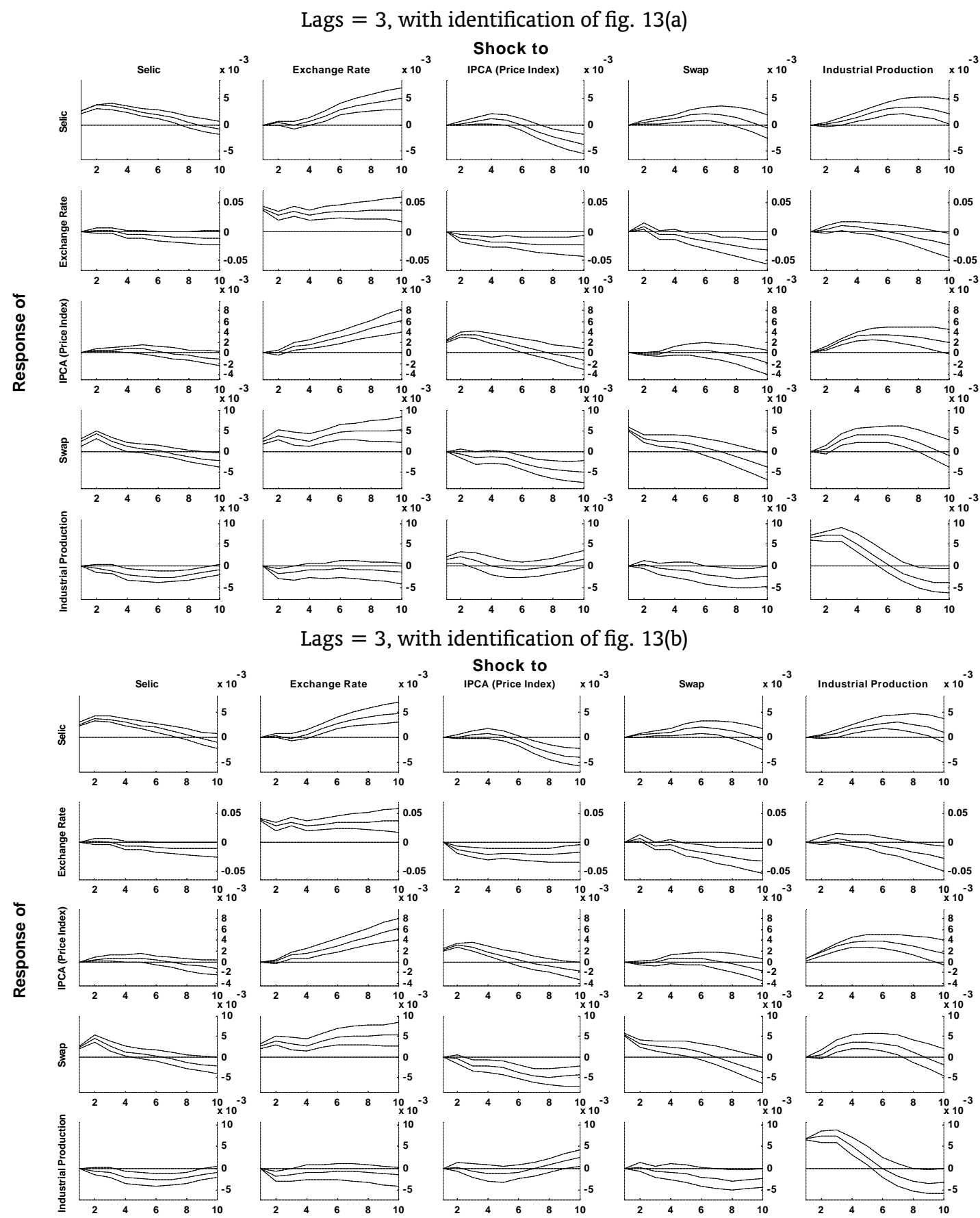


Figure 16 - Pattern of the Benchmark Model with lag Length 2 when TETRAD is Ran After Imposing that Monetary Policy Cannot Respond Contemporaneously to Disturbances in Output

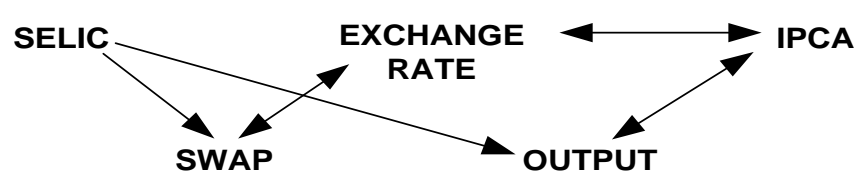

Figure 17 - IRFs of the Model 1999:03 - 2004:12, with 68\% Probability Bands (lags = 2), Assuming that Output Does not Affect SELIC Contemporaneously

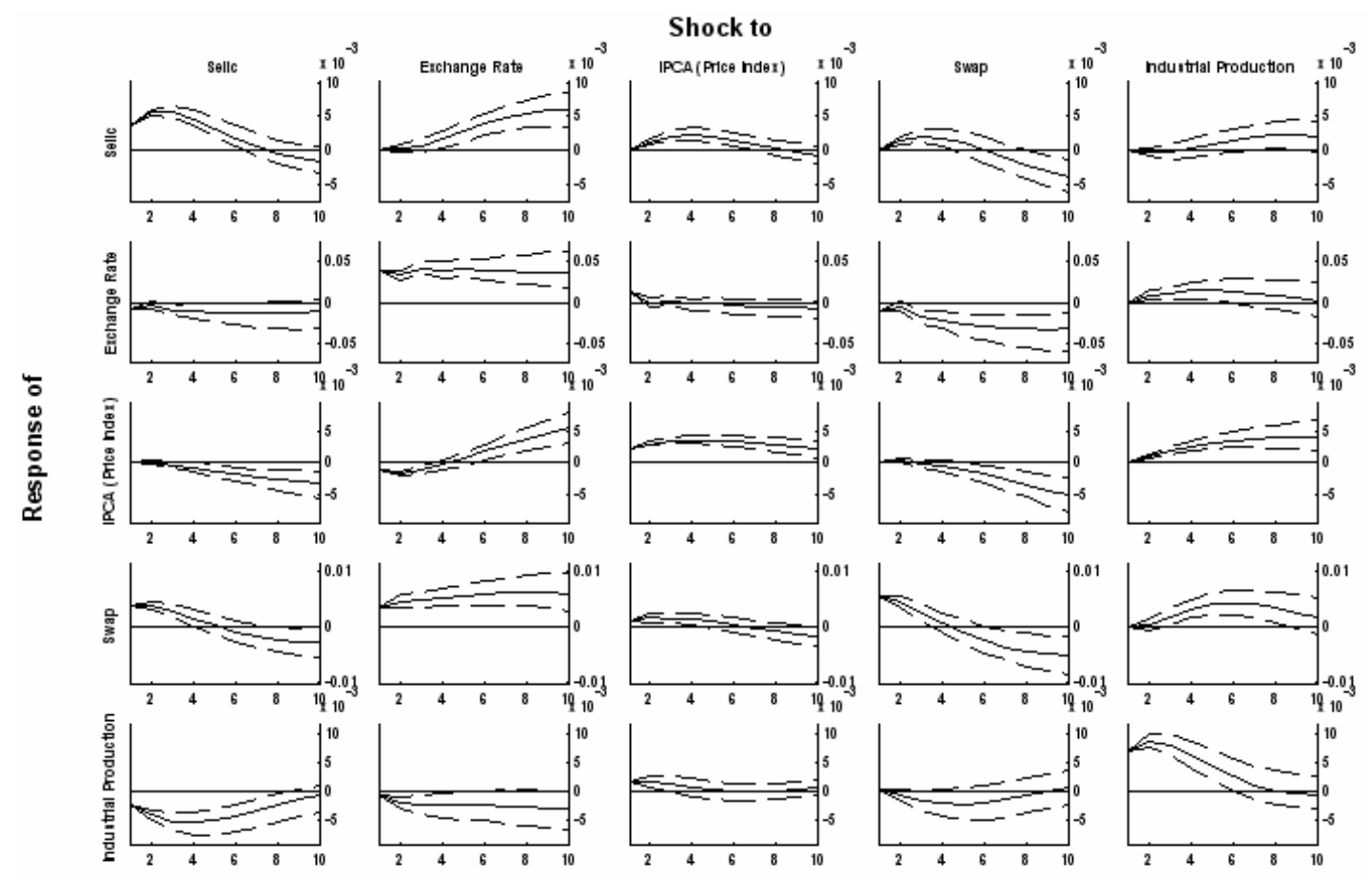

Figure 18 - Pattern of the Model with Inflation Expectations

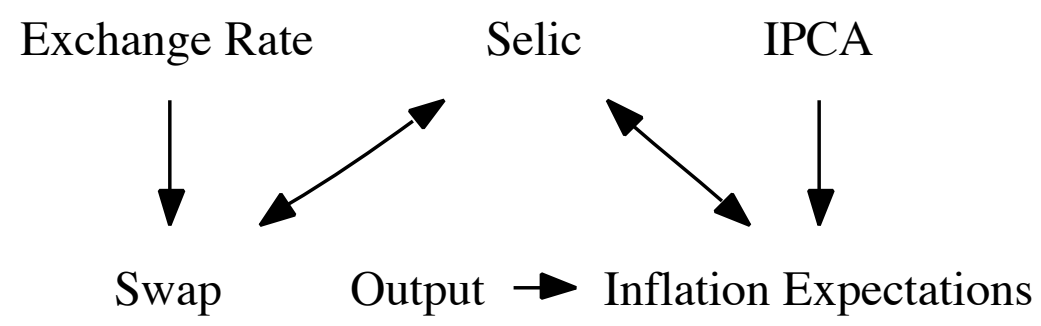


Figure 19 - IRFs of the Model with Inflation Expectations 2001:11 - 2004:12, with 68\% Probability Bands (lags $=2$ ), with Identification given by Figure 18

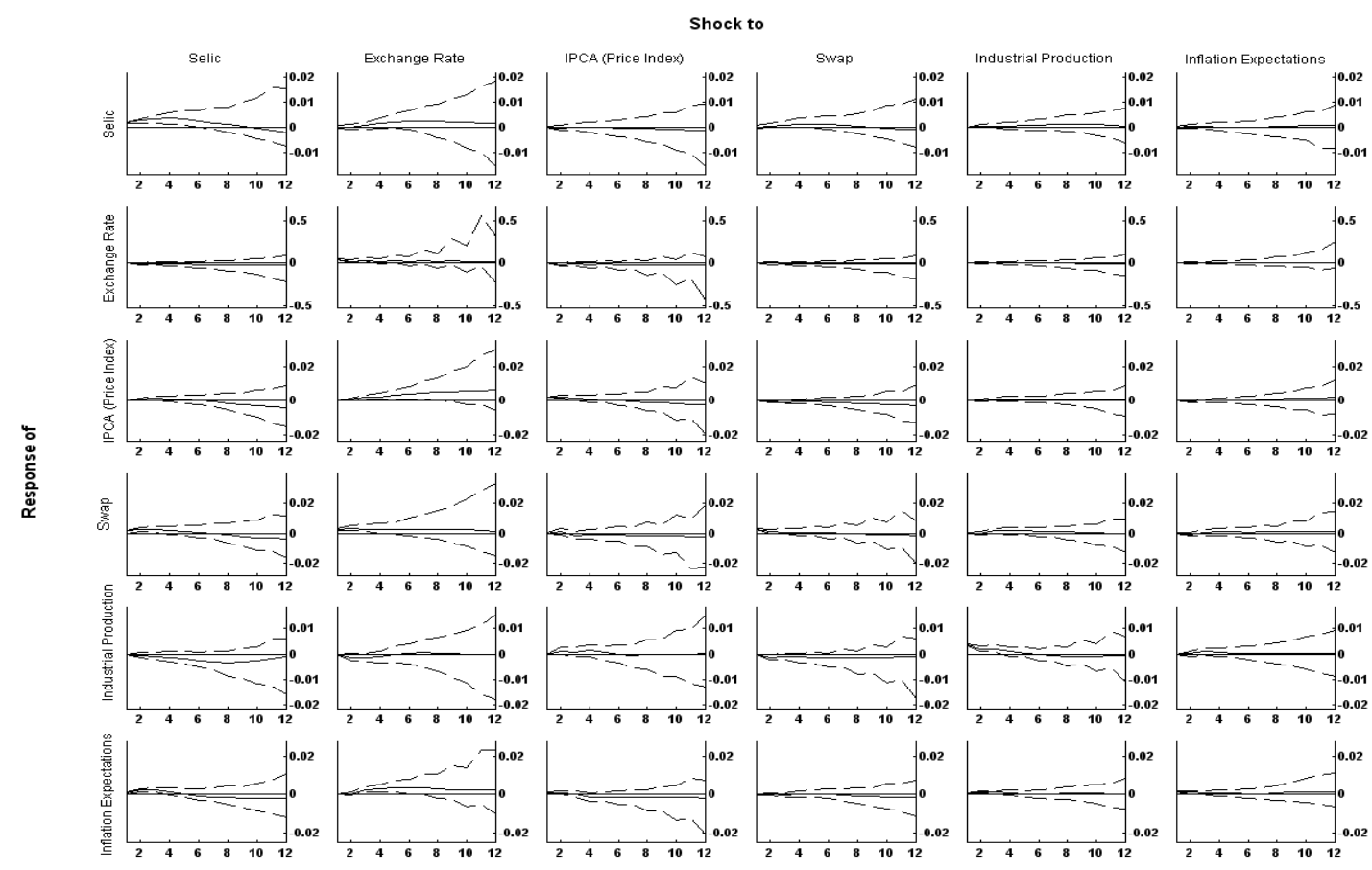

Figure 20 - Pattern of the Alternative Model with Lag Length 1

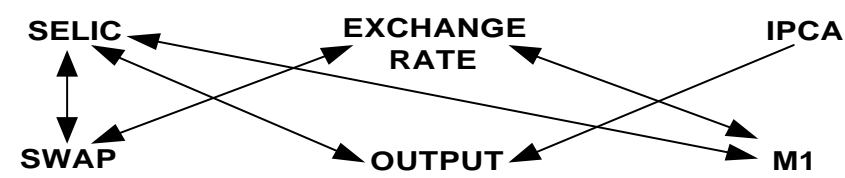

Figure 21 - Pattern of the Alternative Model with Lag Length 2

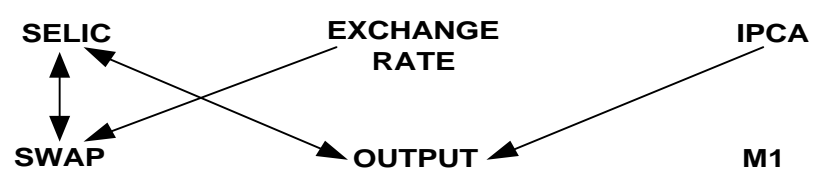


Figure 22 - Pattern of the Alternative Model with Lag Length 3

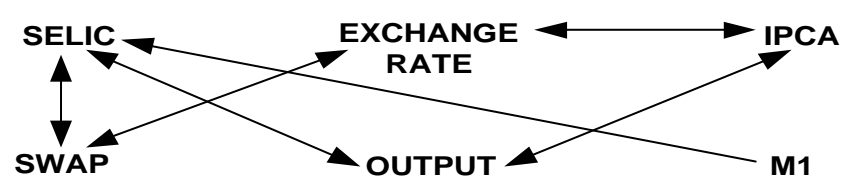

Figure 23 - IRFs of the Alternative Model 1999:03 - 2004:12, with 68\% Probability Bands (lags = 1)

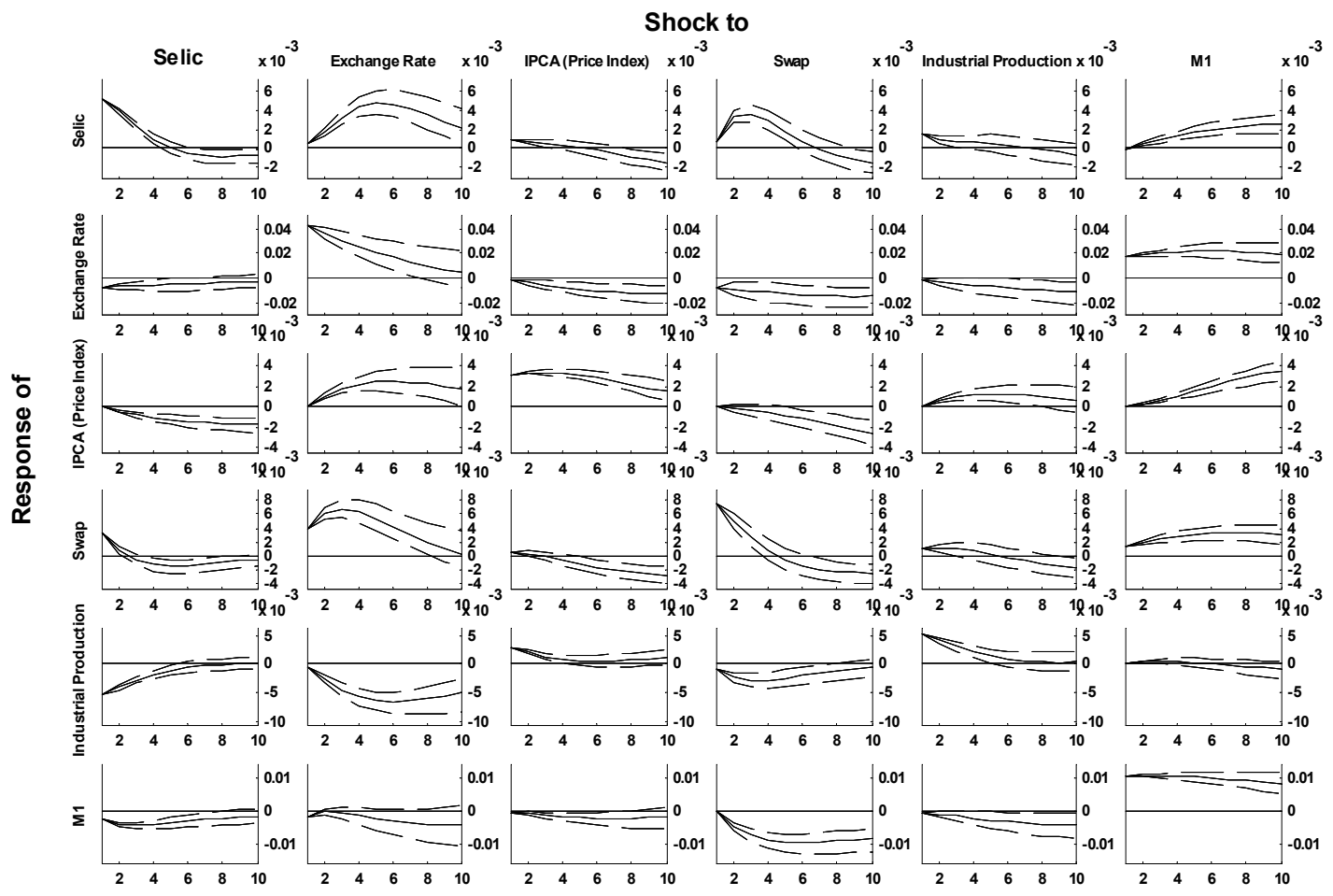


Figure 24 - IRFs of the Alternative Model 1999:03 - 2004:12, with 68\% Probability Bands (lags = 2)

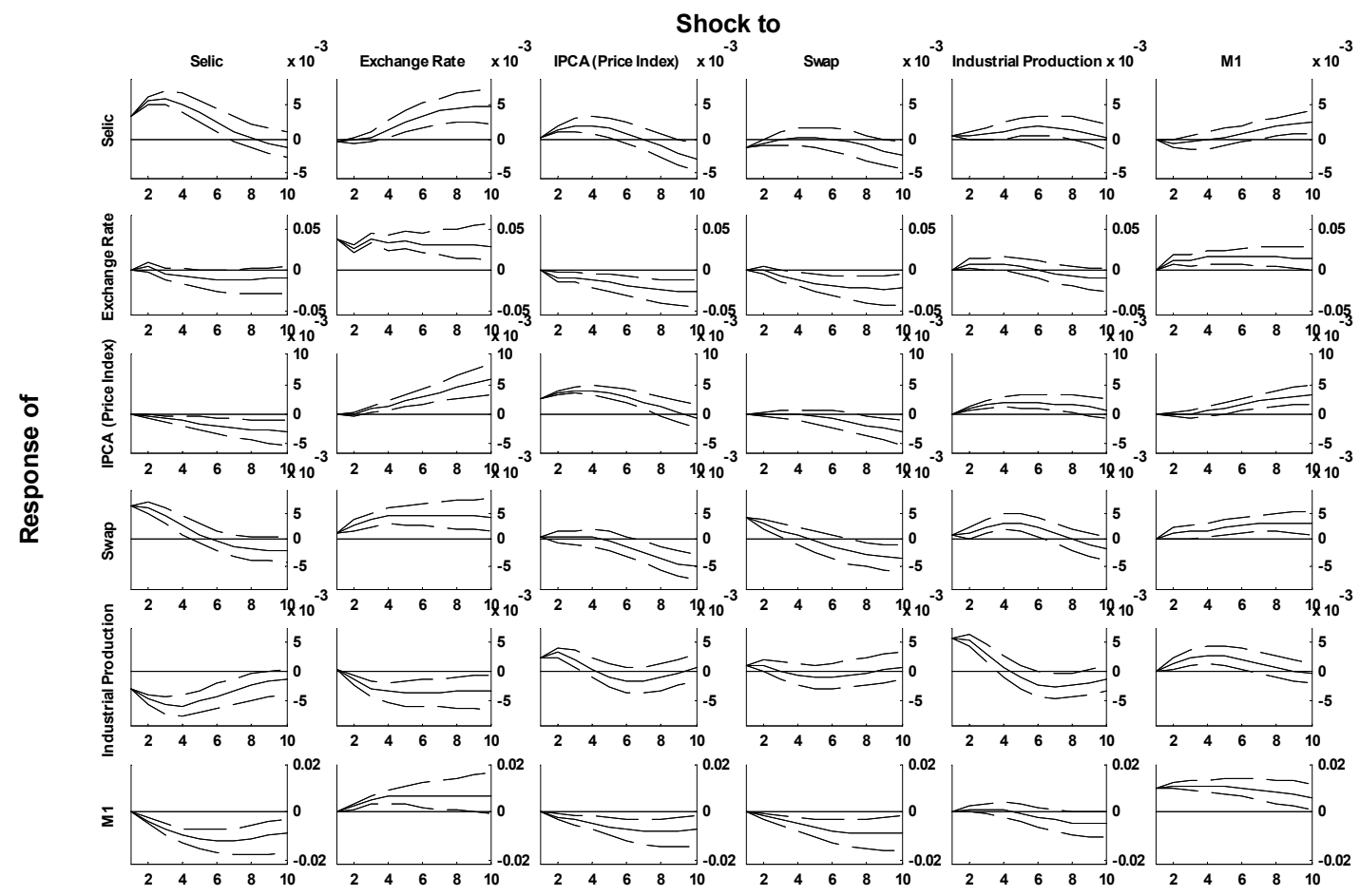


Figure 25 - IRFs of the Alternative Model 1999:03 - 2004:12, with 68\% Probability Bands (lags = 3)

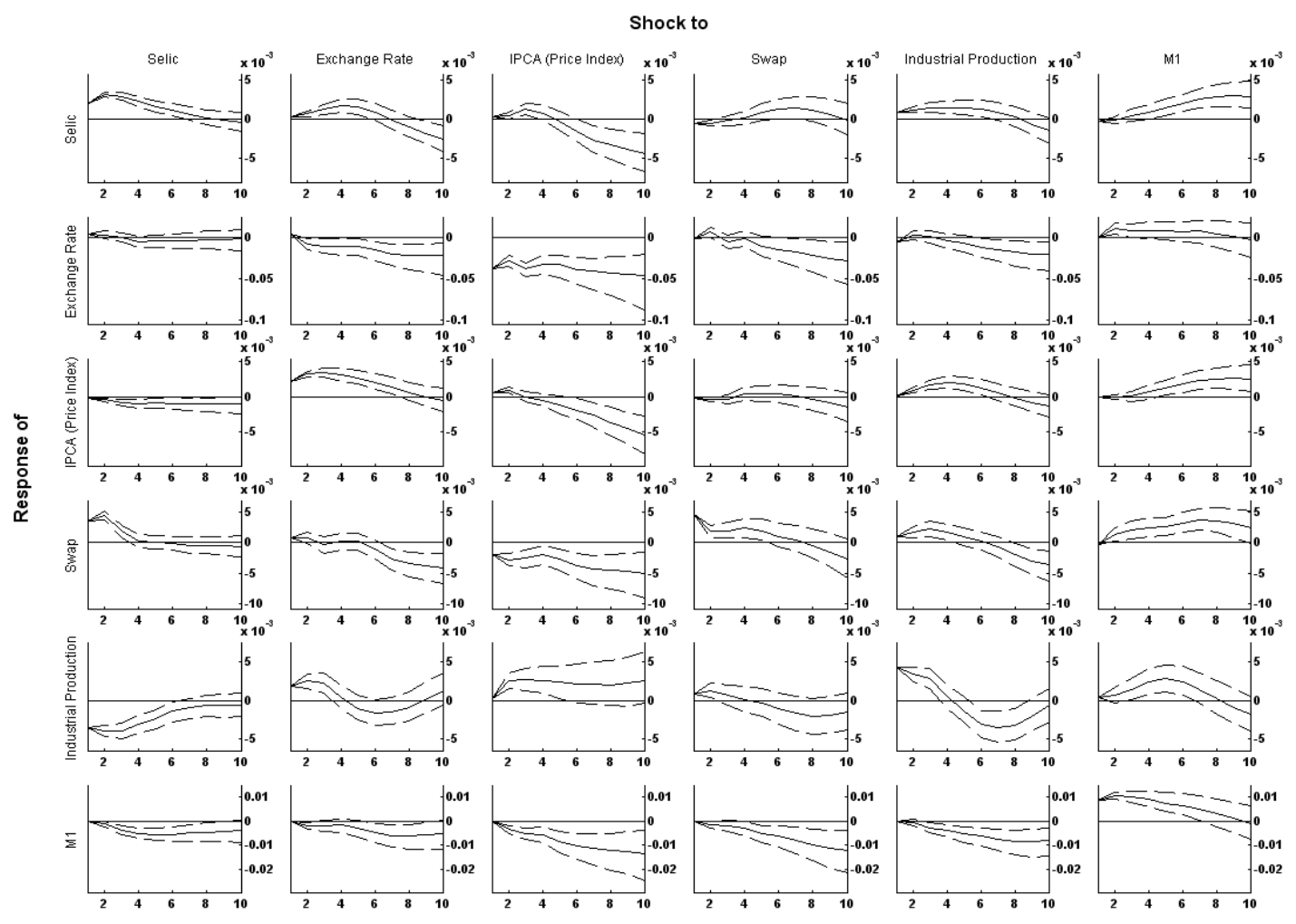




\section{CONCLUDING REMARKS}

At the introduction of this article we noted that the identification problem of VARs have not been satisfactorily solved so far. All the current strategies employed suffer some kind of drawback. This includes the methodology of using directed acyclic graphs (DAGs) to infer the contemporaneous causal order of the variables that we followed in this article to uncover some stylized facts for the Brazilian economy. Notwithstanding the caveats pointed out about inferring causality using DAGs, it seems fair to say that this line of research offers an interesting perspective for studying the identification problem of VARs. Our analysis allows us to conclude a few things. Among these conclusions, we would like to point out three. First, given the various changes in macroeconomic policy during the period after the Real Plan, in order to appropriately conduct an empirical analysis of this period it is important to carefully select subsamples sharing common features. Second, our results showed that unanticipated movements of the exchange have not only large inflationary effect, but also large real effects. This suggests that the exchange rate is an important component in any model aimed toward explaining the behavior of the Brazilian economy after the Real Plan. Third, in contrast with most of the VAR analysis of monetary policy shocks for Brazil, we found empirical evidence that supports the view that contractionary monetary policy shocks indeed reduce the price level. However, this reduction may take as long as six months to become effective. Meanwhile, there is a contraction in the level of economic activity.

\section{Bibliography}

Arquete, L. \& Jayme Jr., F. (2003). Política monetária, preços e produto no Brasil (1994-2002): Uma aplicação de vetores auto-regressivos. Paper presented at the XXXI ANPEC Meeting.

Awokuse, T. \& Bessler, D. (2003). Vector autoregressions, policy analysis, and directed acyclic graphs: An application to the U.S. economy. Journal of Applied Economics, VI(1):1-24.

Bacha, E. (2001). Brazil's Plano Real: A view from the inside. Mimeo.

Barth, M. \& Ramey, V. (2001). The cost channel of monetary transmission. NBER Macroeconomics Annual, pages 199-239.

Bernanke, B. (1986). Alternative explanations of the money-income correlation. Carnegie-Rochester Conference Series on Public Policy, 25:49-100.

Bernanke, B. \& Mihov, I. (1998). Measuring monetary policy. Quarterly Journal of Economics, 113(3):869902.

Bessler, D. \& Lee, S. (2002). Money and prices: U.S. data 1869-1914 (a study with directed graphs). Empirical Economics, 27:427-446.

Blanchard, O. \& Watson, M. (1986). Are all business cycles alike? In Gordon, R., editor, The American Business Cycle: Continuity and Change, pages 123-156. NBER and University of Chicago Press.

Brown, R., Durbin, J., \& Evans, J. (1975). Techniques for testing the constancy of regression relationships over time. Journal of the Royal Statistical Society, Series B, pages 149-163.

Central Bank of Brazil (1999). Monetary policy procedures in brazil. in Monetary policy operating procedures in emerging markets economies. BIS Policy Paper, 5:73-81.

Céspedes, B. \& Lima, E. C. (2003). O desempenho do mercado (Focus) e do BACEN na previsão da inflação: Comparações com modelos lineares univariados. Boletim de Conjuntura IPEA, 60:75-83. 
Christiano, L., Eichenbaum, M., \& Evans, C. (1996). The effects of monetary policy shocks: Evidence from the flow of funds. Review of Economics and Statistics, 78(1):16-34.

Christiano, L., Eichenbaum, M., \& Evans, C. (1999). Monetary policy shocks: What have we learned and to what end? In Taylor, J. \& Woodford, M., editors, Handbook of Macroconomics, pages 65-148. Elsevier. Volume IA.

Christiano, L., Eichenbaum, M., \& Evans, C. (2005). Nominal rigidities and the dynamic effects of a shock to monetary policy. Journal of Political Economy, 113:1-45.

Demiralp, S. \& Hoover, K. (2003). Searching for the causal structure of a vector autoregression. Oxford Bulletin of Economics and Statistics, 65 (Supplement):745-767.

Fackler, P. (1988). Vector autoregressive techniques for structural analysis. Revista de Analisis Economico, 3(2):119-134.

Fernandes, M. \& Toro, J. (2005). O mecanismo de transmissão monetária na economia brasileira pósplano Real. Revista Brasileira de Economia, 59(1):5-32.

Fiorencio, A., Lima, E. C., \& Moreira, A. (1998). Os impactos das políticas monetária e cambial no Brasil pós-plano Real. In A Economia Brasileira Em Perspectiva, pages 27-56. IPEA.

Freedman, D. (2004). Statistical models for causation. Technical report no. 651, Department of Statistics, University of California at Berkeley.

Geiger, D., Verma, T., \& Pearl, J. (1990). Identifying independence in Bayesian networks. Networks, 20:507-534.

Hanson, M. (2004). The 'price puzzle’ reconsidered. Journal of Monetary Economics, 51(7):1385-1413.

Hausman, D. \& Woodward, J. (1999). Independence, invariance and the causal markov condition. British Journal for the Philosophy of Science, 50:521-583.

Heckerman, D., Meek, C., \& Cooper, G. (1999). A Bayesian approach to causal discovery. In Glymour, C. \& Cooper, G., editors, Computation, Causation, and Discovery. MIT Press.

Hoover, K. (2005). Automatic inference of the contemporaneous causal order of a system of equations. Econometric Theory, 21(1):69-77.

Humphreys, P. \& Freedman, D. (1996). The grand leap. British Journal for the Philosophy of Science, 47(1):113-123.

Humphreys, P. \& Freedman, D. (1999). Are there algorithms that discover causal structure? Synthese, 121:29-54.

Hurwicz, L. (1962). On the structural form of interdependent systems. In Logic and Methodology in the Social Sciences, pages 232-239. Stanford University Press.

Kadilaya, K. \& Karlsson, S. (1997). Numerical methods for estimation and inference for Bayesian vector autoregressions. Journal of Applied Econometrics, 12(2):99-132.

Kiiveri, H., Speed, T., \& Carlin, J. (1984). Recursive causal models. Journal of Australian Mathematical Society, 36:30-52.

Koopmans, T. \& Bausch, A. (1959). Selected topics in economics involving mathematical reasoning. SIAM Review, 1:138-148. 
Korb, K. \& Wallace, C. (1997). In search of the philosopher's stone: Remarks to Humphreys and Freedman's critique of causal discovery. British Journal for the Philosophy of Science, 48(4):543-553.

Lauritzen, S. (1996). Graphical Models. Clarendon Press.

Lauritzen, S. (2001). Causal inference from graphical models. In Barndorff-Nielsen, O., Cox, D., \& Klüppelberg, C., editors, Complex Stochastic Systems, pages 63-107. Chapman and Hall/CRC.

Leeper, E. \& Roush, J. (2003). Putting 'M' back in monetary policy. Journal of Money, Credit and Banking, 35 (Part 2):1217-1256.

Lima, E. C. (1990). Inflação e ativos financeiros no Brasil: Uma análise de auto-regressão vetorial. Pesquisa e Planejamento Econômico, 20(1):21-48.

Lima, E. C. \& Sedlacek, G. (1990). Estabilização da taxa de inflação via uma política monetária ativa: Um exercício de simulação. Pesquisa e Planejamento Econômico, 20(2):257-276.

Lopes, F. (2003). Notes on the Brazilian crisis of 1997-99. Revista de Economia Política, 23(3):35-62.

Marques, M. S. B. (1985). A aceleração inflacionária no Brasil: 1973-83. Revista Brasileira de Economia, 39(4):343-384.

Mazon, C. (1985). The impact of government policy on the U.S. steel and cigarette industries. Ph.D. Dissertation. Department of Economics, University of Minnesota.

Minella, A. (2003). Monetary policy and inflation in Brazil (1975-2000): A VAR estimation. Revista Brasileira de Economia, 57(3):605-635.

Moneta, A. (2004). Graphical causal models and VAR-based macroeconometrics. Ph.D. Dissertation. Laboratory of Economics and Management, Sant'Anna School of Advanced Studies.

Montiel, P. (1989). Empirical analysis of high-inflation episodes in Argentina , Brazil , and Israel. IMF Staff Papers, 36(3):527-549.

Pearl, J. (1988). Probabilistic Reasoning in Intelligent Systems. Morgan Kaufmann.

Pearl, J. (2000). Causality: Models, Reasoning, and Inference. Cambridge University Press.

Pearl, J. \& Verma, T. (1991). A theory of inferred causation. In Allen, J., Fikes, R., \& Sandewall, E., editors, Principles of Knowledge Representation and Reasoning: Proceedings of the Second International Conference 11, pages 441-452. Morgan Kaufmann.

Rabanal, P. \& Schwartz, G. (2001). Testing the effectiveness of the overnight interest rate as a monetary policy instrument. In Brazil: Selected Issues and Statistical Appendix. IMF Country Report no. 01/10.

Robins, J., Sheines, R., Spirtes, P., \& Wasserman, L. (2003). Uniform consitency in causal inference. Biometrika, 90(3):491-515.

Robins, J. \& Wasserman, L. (1999). On the impossibility of inferring causation from association without background knowledge. In Glymour, C. \& Cooper, G., editors, Computation, Causation, and Discovery. MIT Press.

Romer, D. (2000). Keynesian macroeconomics without the LM curve. Journal of Economic Perspectives, 14(spring):149-169.

Rothenberg, T. (1971). Identification in parametric models. Econometrica, 39:577-591. 
Sales, A. \& Tannuri-Pianto, M. (2005). Mercado de reserves bancárias e identificação de choques de política monetária para o Brasil. Paper presented at the XXVII Brazilian Meeting of Econometrics.

Sims, C. (1986). Are forecasting models usable for policy analysis? Federal Reserve Bank of Minneapolis Quarterly Review, Winter:1-16.

Sims, C. (1992). Interpreting the macroeconomic time series facts: The effects of monetary policy. European Economic Review, 36(5):975-1000.

Sims, C. (1998). Comment on glenn rudebusch's "does measures of monetary policy in a VAR make sense?”. International Economic Review, 39(4):933-941.

Sims, C., Stock, J., \& Watson, M. (1990). Inference in linear time series models with some unit roots. Econometrica, 58(1):113-144.

Sims, C. \& Uhlig, H. (1991). Understanding unit rooters: A helicopter tour. Econometrica, 59(6):15911599.

Sims, C. \& Zha, T. (1999). Error bands for impulse response. Econometrica, 67(5):1113-1155.

Sims, C. \& Zha, T. (2006). Does monetary policy generate recessions? Macroeconomic Dynamics, 10(2):231-272.

Spirtes, P., Glymour, C., \& Scheines, R. (1993). Causation, prediction, and search. Lecture Notes in Statistics 81 . Springer-Verlag.

Spirtes, P., Glymour, C., \& Scheines, R. (1997). Reply to humphreys and freedman's review of causation, prediction, and search. British Journal for the Philosophy of Science, 48(4):555-568.

Spirtes, P., Glymour, C., \& Scheines, R. (2000). Causation, Prediction, and Search. MIT Press, second edition.

Spirtes, P., Scheines, R., Glymour, C., Richardson, T., \& Meek, C. (2004). Causal inference. In Kaplan, D., editor, Handbook of Quantitative Methodology in the Social Sciences, pages 447-478. Sage Publications.

Stock, J. \& Watson, M. (2001). Vector autoregression. Journal of Economic Perspectives, 15(4):101-115.

Swanson, N. \& Granger, C. (1997). Impulse response functions based on a causal approach to residual orthogonalization in vector autoregressions. Journal of the American Statistical Association, 92(437):357367.

Uhlig, H. (2005). What are the effects of monetary policy on output? Results from an agnostic identification procedure. Journal of Monetary Economics, 52:381-419.

Verma, T. \& Pearl, J. (1988). Causal networks: Semantics and expressiveness. In Proceedings of the Fourth Workshop in Artificial Intelligence, pages 352-359.

Woodward, J. (1997). Explanation, invariance, and intervention. Philosophy of Science, 64:S26-S41.

Woodward, J. (2001). Causation and manipulability. In Stanford Encyclopedia of Philosophy.

Zhang, J. (2002). Consistency in causal inference under a variety of assumptions. Masters Thesis. Department of Philosophy, Carnegie Mellon University.

Zhang, J. \& Spirtes, P. (2003). Strong faithfulness and uniform consistency in causal inference. In Proceedings of the 19th Annual Conference on Uncertainty in Artificial Intelligence, pages 632-639. Morgan Kaufmann Publishers. 


\section{APPENDIX I THE SPIRTES-GLYMOUR-SCHEINES MODEL}

A (causal) directed graph is a picture that represents a causal flow, indicated by arrows (directed edges) between some pair of vertices (variables)..$^{50}$ An edge in a graph can be either directed (marked by a single arrowhead on the edge) or undirected (unmarked). If all edges of a graph are directed, we say that it is a directed graph. Arrows represent causal relationships: if there is an arrow pointing from $X_{i}$ to $X_{j}$ it means that $X_{i}$ has a direct causal effect on $X_{j}$, relative to all vertices. A directed path of length $\mathrm{n}$ between vertices $X$ and $Y$ is a sequence of $\mathrm{n}$ vertices starting at $X$ and ending at $Y$ of the form $X \rightarrow V_{1} \rightarrow V_{2} \rightarrow \cdots \rightarrow V_{n-2} \rightarrow Y$ or of the form $X \leftarrow V_{1} \leftarrow V_{2} \leftarrow \cdots \leftarrow V_{n-2} \leftarrow Y$. A Directed Acyclic Graph (DAG) ${ }^{51}$ is a directed graph with no directed cycle, in that one cannot start at a vertex (variable) and follow a directed path back to that vertex. The vertex $X_{i}$ is in the set of 'parents' of a variable $X_{j}$ in a DAG G, denoted by $P A_{G}\left(X_{j}\right)$, if there is an edge $X_{i} \rightarrow X_{j}$ in $G$. $X_{j}$ is a 'descendent' of $X_{i}$ in $G$ if there is a directed path from $X_{i}$ to $X_{j}$ or $X_{i}=X_{j}$.

The SGS model begins with a triple $\langle G, V, P\rangle$, where $G$ is a DAG with a non-empty set of vertices (variables) $V, V=\left(X_{1}, X_{2}, \ldots, X_{k}\right)$ is a vector of random variables and $P$ is a joint probability distribution for $V$. Since the goal of causal inference is to gain some information about causation from the information about association, there must be some assumptions that connect them. These assumptions are the Causal Markov Condition and faithfulness.

Definition .1 (Distribution Markov to $G$ or "Compatible" with $G$ ). A distribution $P$ with density function $p$ is 'Markov' to $G$ if $p\left(x_{1}, \ldots, x_{k}\right)=\prod_{i=1}^{k} p\left\{x_{i} \mid p a_{G}\left(x_{i}\right)\right\}$, where $p\left\{x_{i} p a_{G}\left(x_{i}\right)\right\}=p\left(x_{i}\right)$ when $p a_{G}\left(x_{i}\right)=$ $\emptyset$. This formula is called the 'Markov factorization' of $P$ according to $G$.

Let $P(G)$ be all distributions that are Markov to $G$. If $P$ is in $P(G)$ then $P$ is 'compatible' with $G$.

The next proposition was first stated in Pearl and Verma (1991), but it is implicit in the works of Kiiveri et al. (1984) and others.

Proposition .2 (The Causal Markov Condition). Any distribution generated by a Markovian Model $G$ is Markov to $G .52$

A model is 'Markovian'53 if a DAG can represent it and all the error terms are jointly independent. The Causal Markov Condition states that if $\mathrm{G}$ represents the data generating mechanism for $P$, and $G$ is Markovian, then $P \in P(G)$. A simple proof of Proposition 1 is given in Pearl (2000, p. 30).

Let $P \in P(G)$ and let $\varphi(P)$ represent all independence and conditional independence relations that hold for the variables in $V$ under $P$. Let $\varphi_{G}$ be all independence and conditional independence relationships that are common to all the distributions in $P(G)$.

Definition .3. (Faithfulness): $P$ is 'faithful' to $G$ if $\varphi(P)=\varphi_{G}$.

Therefore $P$ is faithful if it does not possess extra independence relationships not shared by all the other distributions in $P(G)$. As Spirtes-Glymour-Scheines say: 'the Faithfulness Condition can be thought of as the assumption that conditional independence relations are due to causal structure rather [than] to accidents of parameters values'.

A convenient way of characterizing the set of distributions that belongs to $P(G)$ is to list the set of all independence and conditional independence relations that belongs to $\varphi_{G}$. These independencies can be read off $G$ using a graphical criterion called $d$-separation (where $d$ stands for directional, Pearl (1988)). Consider three disjoint sets of variables $X, Y$, and $Z$, which are represented as vertices in $G$.

\footnotetext{
${ }^{50}$ This section draws extensively on Robins et al. (2003).

${ }^{51}$ References on directed acyclic graphs include Lauritzen (1996) and Pearl (2000).

${ }^{52}$ For a discussion of the concept of causality used here (due to Judea Pearl and others) see Woodward (2001).

${ }^{53}$ Pearl (2000).
} 
To test whether $X$ is independent of $Y$ given $Z$ in any distribution that belongs to $P(G)$, we need to test whether the vertices corresponding to variables $Z$ "block" all paths from vertices in $X$ to vertices in $Y$. Blocking is to be interpreted as stopping the flow of information (or of dependency) between the variables that are connected by such paths, as defined next.

Definition .4 ( $d$-separation). A path $p$ is said to be $d$-separated (or blocked) by a set of vertices $Z$ if and only if

1. $p$ contains a chain $i \rightarrow m \rightarrow j$ or a fork $i \leftarrow m \rightarrow j$ such that the middle vertex $m$ is in $Z$, or

2. $p$ contains an inverted fork (or collider) $i \rightarrow m \leftarrow j$ such that the middle vertex $m$ is not in $Z$ and such that no descendant of $m$ is in $Z$.

A set $Z$ is said to $d$-separate $X$ from $Y$ if and only if $Z$ blocks every path from a vertex in $X$ to a vertex in $Y$.

Figure 26 - The Representation of Dependencies among Five Variables

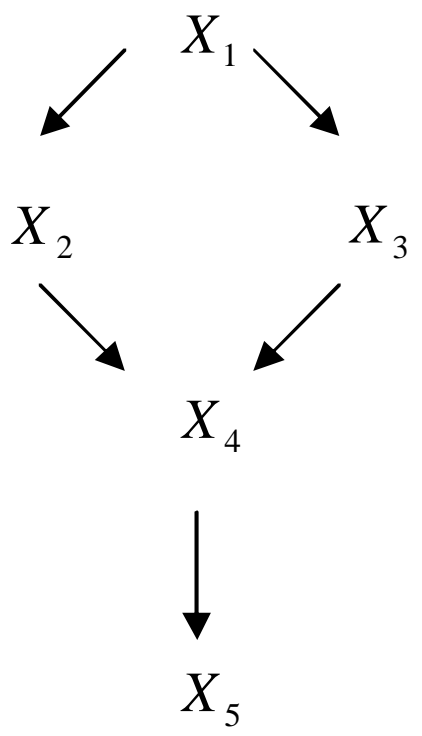

In figure 26, $X=X_{2}$ and $Y=X_{3}$ are $d$-separated by $Z=X_{1}$, because both paths connecting $X_{2}$ and $X_{3}$ are blocked by $Z$. The path $X_{2} \leftarrow X_{1} \rightarrow X_{3}$ is blocked because it is a fork in which the middle vertex $X_{1}$ is in $Z$, while the path $X_{2} \rightarrow X_{4} \leftarrow X_{3}$ is blocked because it is an inverted fork in which the middle vertex $X_{4}$ and all its descendants are outside $Z$. However, $X$ and $Y$ are not $d$-separated by the set $Z^{\prime}=X_{1}, X_{5}$ : the path $X_{2} \rightarrow X_{4} \leftarrow X_{3}$ (an inverted fork) is not blocked by $Z$ ', since $X_{5}$, a descendant of the middle vertex $X_{4}$, is in $Z^{\prime}$.

In order to distinguish between the probabilistic notion of conditional independence and the graphical notion of d-separation, we will use $(X|| Y \mid Z)_{P}$ to denote the independence of $X$ and $Y$ given $Z$ in the former notion and $(X|| Y \mid Z)_{G}$ for the later notion. The following proposition due to Verma and Pearl (1988) and Geiger et al. (1990) shows that there is a one-to-one correspondence between the probabilistic and graphical notions of conditional independence: ${ }^{54}$

\footnotetext{
$\overline{{ }^{54} \text { For a sketch of the proof see Pearl (2000). }}$
} 
Proposition .5. For any three disjoint subsets of vertices $(X, Y, Z)$ in a DAG $G$ and for all probability functions $P$, we have:

(i) $(X \underline{\|}|Y| Z)_{G} \Rightarrow(X \underline{\|}|Y| Z)_{P}$ whenever $P \in P(G)$, and

(ii) if $(X|| Y \mid Z)_{P}$ holds in all distributions in $P(G)$ (faithfulness), then it follows that $(X|| Y \mid Z)_{P} \Rightarrow$ $(X|| \bar{Y} \mid Z)_{G}$

Equations (3) in the text are a system of linear equations, where each variable (reduced form residual) is a linear function of its direct causes and an error term (structural residual), with error terms independent of each other. If the graph $G$ that represents the model has no cycles (is a DAG) then the variables are generated by a Markovian model. Therefore, the model satisfies the property that guarantees the compatibility between its distribution function and graph $\mathrm{G}$. Because conditional independence implies zero partial correlation, Proposition 2 translates into a graphical test for identifying those partial correlations that must vanish in the model. 


\section{APPENDIX II - CONSISTENCY OF TESTS}

Let $O$ be the set observed random variables, of which $O^{n}=\left\{O_{1}, \ldots, O_{n}\right.$ denotes an i.i.d. sample, and let $P^{n}$ be the n-fold product measure corresponding to $P .{ }^{55} \Gamma$ is the set of all possible causal graphs over $O$. Given any $G \in \Gamma, \Omega(G)$ denotes the set of distributions that are Markov and Faithful to $G . \Omega_{\Gamma}$ is defined as $\cup_{G \in \Gamma} \Omega(G)$.

A test $\phi$ is a sequence of functions $\left(\phi_{1}, \phi_{2}, \ldots, \phi_{n}, \ldots\right)$ where each $\phi_{I}$ takes data $O^{i}$ and returns 0,1 , or 2 , representing "acceptance", "rejection", or "no conclusion", respectively. Let $\theta$ be any causal parameter of interest, which is in general a function of the probability distribution $P$ and the causal graph $G$. With respect to the null hypothesis $H_{0}: \theta=\theta_{0}$ against the alternative $H_{1}: \theta \neq \theta_{0}$, we define

$$
\begin{aligned}
& \Omega_{\Gamma 0}=\left\{P: \exists G \in \Gamma\left[P \in \Omega(G) \wedge T(P, G)=\theta_{0}\right]\right\} \\
& \Omega_{\Gamma 1}=\left\{P: \exists G \in \Gamma\left[P \in \Omega(G) \wedge T(P, G) \neq \theta_{0}\right]\right\}
\end{aligned}
$$

A test which always reports "no conclusion" is not useful. We exclude such uninformative tests by considering only non-trivial ones in the following sense:

Definition .6 (non-triviality). A test $\phi$ is non-trivial iffor some $P \in \Omega_{\Gamma}$ and some $j \in\{0,1\}$,

$$
\lim _{n \rightarrow \infty} P^{n}\left\{\phi_{n}\left(O^{n}\right)=j\right\}=1
$$

Definition .7 (pointwise consistency). A test $\phi$ is pointwise consistent if

(i) for every $P \in \Omega_{\Gamma 0}, \lim _{n \rightarrow \infty} P^{n}\left\{\phi_{n}\left(O^{n}\right)=1\right\}=0$ and

(ii) for every $P \in \Omega_{\Gamma 1}, \lim _{n \rightarrow \infty} P^{n}\left\{\phi_{n}\left(O^{n}\right)=0\right\}=0$

Definition .8 (uniform consistency). A test $\phi$ is uniform consistent if

(i) for every $P \in \Omega_{\Gamma 0}, \lim _{n \rightarrow \infty} \sup _{P \in \Omega_{\Gamma 0}} P^{n}\left\{\phi_{n}\left(O^{n}\right)=1\right\}=0$ and

(ii) for every $\delta>0, \lim _{n \rightarrow \infty} \sup _{P \in \Omega_{\Gamma 1 \delta}} P^{n}\left\{\phi_{n}\left(O^{n}\right)=0\right\}=0$

where $\Omega_{\Gamma 1 \delta}=\left\{P: \exists G \in \Gamma\left[P \in \Omega(G) \wedge\left|T(P, G)-\theta_{0}\right| \geq 0\right]\right\}$

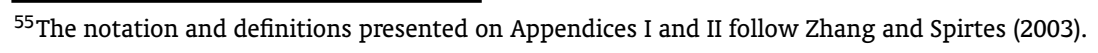

